\title{
Interactions of amino acids and aminoxazole derivatives: cocrystal formation and prebiotic implications enabled by computational analysis
}

\author{
Nieves Lavado Juan García de la Concepción Reyes Babiano Pedro Cintas and \\ Mark E. Light
}

Nieves Lavado* Juan García de la Concepción* Reyes Babiano Pedro Cintas

Departamento de Química Orgánica e Inorgánica, Facultad de Ciencias-UEX, Avenida de Elvas s/n, E-06006 Badajoz, Spain

E-mail: nlavador@gmail.com,jugarco@unex.es

M. E. Light

Department of Chemistry, Faculty of Natural and Environmental Sciences, University of Southampton, Southampton SO17 1BJ, UK

May, $7^{\text {th }} 2019$

\begin{abstract}
In line with the postulated intermediacy of aminoxazoles derived from small sugars toward the direct assembly of nucleoside precursors, we show here a potential prebiotic scenario where aminoxazolines might have also played further roles as complexing and/or sequestering agents of other primeval blocks, namely amino acids. To this end, a bisaminoxazoline derivative, generated from dihydroxyacetone and cyanamide, gives rise to stable co-crystal forms with dicarboxylic amino acids (Asp and Glu), while ionic interactions owing to proton transfer are inferred from spectroscopic data in aqueous solution. The structure of a 1:2 aminoxazoline: aspartic acid complex, discussed in detail, was elucidated by X-ray diffractometry. Optimized geometries of such ionic structures with bulk aqueous solvation were assessed by DFT calculations, which disclose preferential arrangements that validate the experimental data. Peripherally, we were able to detect in a few cases amino acid dimerization (i.e. dipeptide formation) after prolonged incubation with the bis-aminoxazole derivative. A mechanistic simulation aided by computation provides some predictive conclusions for future explorations and catalytic design.
\end{abstract}


Keywords Prebiotic chemistry · Amino acids - Aminoxazole chemistry · Reaction mechanism · Dipeptide

\section{Introduction}

Prebiotic chemistry deals with a vast repertoire of chemical reactions and physical processes aimed at elucidating the endogenous origin of essential building blocks and biomolecules on the primitive Earth, as well as their exogenous formation in space and subsequent delivery onto our planet by cometary or meteoritic impacts (Eschenmoser 2011; Ruiz-Mirazo et al. 2014). It is often assumed that the primeval soup consisted of a complex mixture where, in addition, several and disparate chemical routes coexisted and interacted each other. This inherent complexity, which often results in very low yields of individual components, contrasts with our conventional bench chemistry aimed at synthesizing a few compounds in high yields. The situation might not be so nightmarish whether some reactions and physical processes were able to favor selective transformations and sorting out over cascade and multistep scenarios (Schwartz 2007; Schwartz 2013; Budin and Szostak 2010; Pressman et al. 2015). Thus, rac-ribose, obtained in an extremely low yield $(<1 \%)$ from the messy formose reaction, would have instead been favored through the alkaline condensation of glycolaldehyde phosphate and formaldehyde as demonstrated by Eschenmoser et al. (Müller et al. 1990; Krishnamurthy et al. 1999). Higher sugars arose likely from C2 or C3 aldehydes via the formose reaction and, like ribose, their abundance would have been scarce.

A rather iconoclastic alternative to the RNA world, is Sutherland's aminoxazolebased chemistry by which a seemingly simple bottom-up construction of pyrimidine ribonucleotides can be achieved from purely prebiotic molecules like cyanamide, glycolaldehyde, glyceraldehyde, cyanoacetylene, and inorganic phosphate (Borsenberger et al. 2004; Anastasi et al. 2006; Powner et al. 2009; Powner et al. 2010; Powner et al. 2012; Ritson and Sutherland 2012). In subsequent work, Sutherland's group devised a proto-metabolic scenario where C2 and C3 sugars merge with HCN and its derivatives under photoredox catalysis (Patel et al. 2015). By focusing on dihydroxyacetone, which exists in equilibrium with glyceraldehyde (Yaylayan et al. 1999), extra products can be envisaged such as phosphorylated glycerols (precursors 
of lipid membranes) together with nucleosides, $\alpha$-aminonitriles (precursors of amino acids) and nucleotides, thereby broadening the scope of synthetic prebiotic chemistry.

Simpler structural models might however throw light on non-covalent interactions and reactions involving different scaffolds. It is well established in carbohydrate chemistry that aldoses react with inorganic cyanates or thiocyanates affording glyco-oxazolidinones or glycol-oxazolidinethiones respectively, whereas ketoses often lead to cyclic and spiranic structures (Grouiller et al. 1988; Kovács et al. 1995). Thus, a prebiotic ketone, dihydroxyacetone (1), does react with KOCN, KSCN, or cyanamide giving rise to spiranic bicycles (Scheme 1) (Saul et al. 2002). The reaction with cyanamide is especially noticeable as the resulting bis(2-aminoxazoline), namely 2,7-diamino-1,6-dioxa-3,8diazaspiro[4,4]nonan-2,7-diene (4), could also interact with other aldoses or primeval monomers, thereby fueling further chemistry. Compound $\mathbf{4}$ is thus structurally related to other aminoxazole derivatives like 2-amino-D-ribofurano[2,1-d]-2-oxazoline (5, Scheme 2), though less conformationally flexible than the latter. Moreover, and interestingly, such spiranes are chiral due to axial stereogenicity.

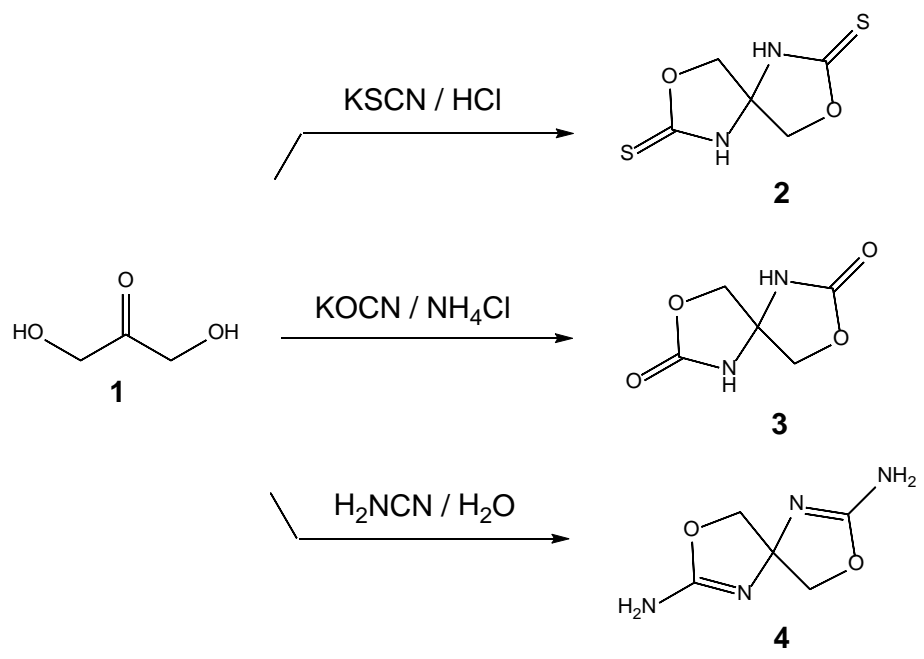

Scheme 1 Condensation reactions of dihydroxyacetone with (thio)cyanates or cyanamide.

As mentioned, ribo-oxazoline 5 can likewise be obtained from D-ribose and cyanamide at basic pH according to previous protocols (Springsteen and Joyce 2004). This aminoxazoline derivative degrades more slowly than ribose itself (ca. 70 -fold at $\mathrm{pH} \sim 10, t_{1 / 2}>1$ week), thus being a masked form of the free sugar that could have boosted its stability and accumulation. 
In fact, the bicyclic adduct from ribose and cyanamide crystallizes spontaneously in aqueous solution, while the corresponding products derived from other hexoses and the rest of pentoses do not (Springsteen and Joyce 2004). Compound 5 generated from enantiomerically pure D-ribose is obviously chiral. De novo synthesis from rac-glyceraldehyde and 2aminoxazole, or alternatively from D- and L-ribose plus cyanamide, affords the racemic derivative, although the use of scalemic glyceraldehyde still enables enantioselective synthesis of 5 (Anastasi et al. 2006). In an elegant asymmetric variation, Blackmond and associates (Hein et al. 2011) showed that highly enantioenriched sugar aminoxazolines could be obtained from racemic starting materials with the handedness provided solely by a small enantiomeric imbalance of amino acids present in the reaction mixture (Scheme 2). Thus, a sample of L-proline (with an initial 1\% ee) was added to a mixture of rac-glyceraldehyde and 2-aminoxazole and the ensuing reaction afforded both D-ribo- and D-arabino-configured aminoxazolines in $20-80 \%$ ee. Cooling the mixture to $4{ }^{\circ} \mathrm{C}$ promoted crystallization of enantiopure D-ribo-aminoxazoline (5) crystals. The unnatural L-ribo-aminoxazoline was obtained similary starting from a $1 \%$ ee of the D-proline enantiomer. Remarkably, Lglyceraldehyde could be sequestered by a side reaction joining L-proline and the aminoxazoline, (shown in Scheme 2), thereby enabling kinetic resolution of glyceraldehyde.
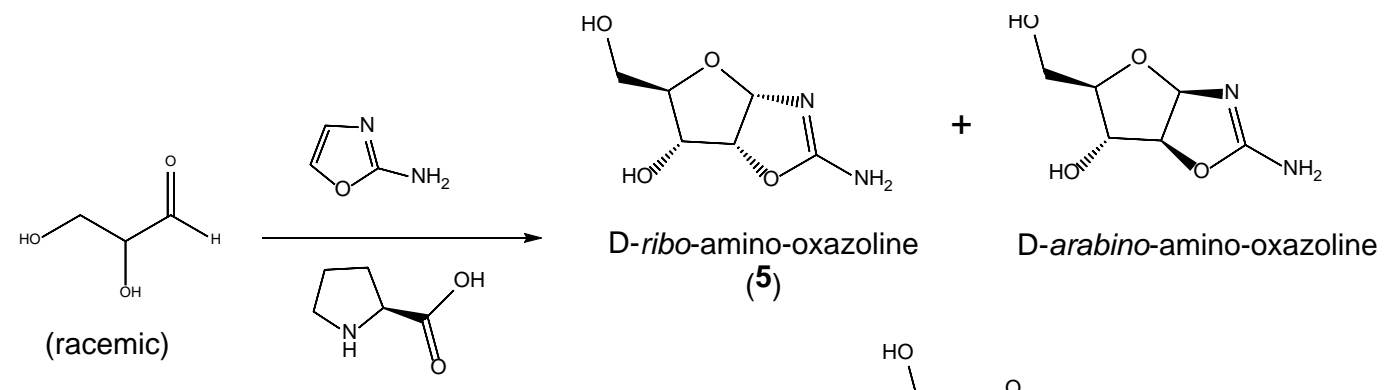

(5)

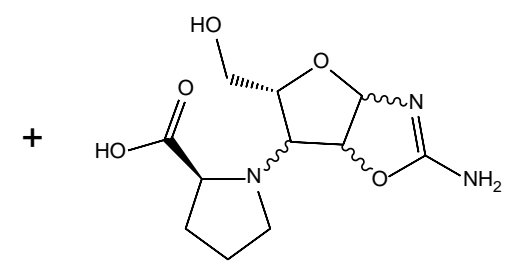

Scheme 2 Formation of enantioenriched RNA precursors from racemic glyceraldehyde in the presence of a chiral amino acid.

The present study shows the interactions of the above-mentioned aminoxazoline heterocycles, 4 in particular, with some proteinogenic amino acids, whose structures have 
been assessed by experimental and computational tools, which unravel less-explored mechanisms of accumulation and delivery of biomolecules in prebiotic niches (Schwartz 2007; Budin and Szostak 2010). Stable solid phases were obtained for dicarboyxlic amino acids (Asp and Glu), and characterized in detail for the cocrystal of $\mathbf{4}$ and Asp. The serendipitious observation that amino acid dimerization took place in a few cases to a minor extent, prompted us to search for a mechanistic rationale for the role of such complexes as condensing agents.

\section{Materials and methods}

All reagents were obtained from Aldrich-Sigma ${ }^{\circledR}$ and used as received without further purification. Aqueous solutions were prepared in bidistilled water. Compounds 4 (Saul et al. 2000) and 5 (Borsenberger et al. 2004) were prepared according to previously described methods.

IR spectra were recorded in the range of $4000-600 \mathrm{~cm}^{-1}$ on an FT-IR Thermo spectrophotometer using $\mathrm{KBr}$ (Merck) pellets. NMR spectra were recorded in $\mathrm{D}_{2} \mathrm{O}$ solutions on a Bruker instrument operating at $500 \mathrm{MHz}$ and $125 \mathrm{MHz}$ for ${ }^{1} \mathrm{H}$ and ${ }^{13} \mathrm{C}$ nuclei, respectively. TMS was used as the internal standard $(\delta=0.00 \mathrm{ppm})$. Optical rotations were measured at $25^{\circ} \mathrm{C}$ on a Perkin-Elmer 241 polarimeter at $\lambda=589 \mathrm{~nm}$ (D line, Na lamp), with all concentrations given in $\mathrm{g} / \mathrm{mL}$. Analytical microanalyses were determined on a Leco CHNS-932 analyzer.

Electrospray ionization mass spectra were analyzed using a 6520 Accurate-Mass Q-TOF LC/MS instrument with DUAL ESI interface (Agilent Technologies) coupled to an Agilent 1200 Liquid Chromatography (LC) apparatus. All samples were introduced in the system using injector and column switching valve directly to the interface. The mobile phase was milli-Q water containing $1.0 \%$ acetic acid with a flow at $0.3 \mathrm{~mL} / \mathrm{min}$. The acid imparts a positive charge on some functional groups; all samples were run in positive scan mode only. Mass spectra were recorded from 40 to $1000 \mathrm{~m} / \mathrm{z}$ values in high-resolution mode (at $4 \mathrm{GHz}$ $\mathrm{ADC}$ rate for data acquisition) and real-time processing on the mass peaks detected in each transient, weighting the apex data much more heavily than the shoulders. Conditions in the nebulizer were $350{ }^{\circ} \mathrm{C}$ (gas temperature), with a flow rate of $6 \mathrm{~mL} / \mathrm{min}$ and $60 \mathrm{psi}$. 
Complexation of 4 with DL-Asp (1:1): A mixture of bis(aminoxazoline) 4 (0.20 g, 1.28 mmol), DL-Asp (0.17 g, $1.28 \mathrm{mmol}$ ), and water $(4 \mathrm{~mL})$ was heated at $\sim 50{ }^{\circ} \mathrm{C}$ until complete dissolution. Then, it was kept at $4{ }^{\circ} \mathrm{C}$ and $\mathrm{MeOH}$ was gradually added giving rise to a white precipitate. The first crop, obtained after addition of small volumes of $\mathrm{MeOH}$ (up to $5 \mathrm{~mL}$ ), consisted essentially of DL-aspartic acid. The solid was filtered off and subsequent addition of $\mathrm{MeOH}$ (up to $18 \mathrm{~mL}$ ) to the mother liquors afforded a crystalline solid (6, $0.098 \mathrm{~g}, 37 \%$ ), $\mathrm{mp}=155^{\circ} \mathrm{C}$ (dec.), whose spectroscopic and X-ray diffraction data agree with formation of the title complex (6) as a dihydrate. Anal. calcd for $\mathrm{C}_{13} \mathrm{H}_{22} \mathrm{~N}_{6} \mathrm{O}_{10} \cdot 2 \mathrm{H}_{2} \mathrm{O}: \mathrm{C}, 34.06 ; \mathrm{H}, 5.72$; N, 18.33; found: C, 33.77; H, 5.40; N, 18.30.

Complexation of 4 with L-Glu (1:2): A mixture of 4 (0.20 g, $1.28 \mathrm{mmol})$, L-Glu (0.38 g, $2.56 \mathrm{mmol})$, and water $(8 \mathrm{~mL})$ was heated at $\sim 50{ }^{\circ} \mathrm{C}$. The resulting solution was kept at $4{ }^{\circ} \mathrm{C}$ with successive additions of $\mathrm{MeOH}$ (small portions until a final volume of $18 \mathrm{~mL}$ ), thus leading to the formation of a white solid (7, $0.38 \mathrm{~g}, 66 \%), \mathrm{mp}=191{ }^{\circ} \mathrm{C},[\alpha]_{\mathrm{D}}=+2.5(c=$ 0.008, $\mathrm{H}_{2} \mathrm{O}$ ). Anal. calcd for $\mathrm{C}_{15} \mathrm{H}_{26} \mathrm{~N}_{6} \mathrm{O}_{10} \cdot 2 \mathrm{H}_{2} \mathrm{O}$ : C, 37.04; H, 6.22; N, 17.28; found: C, 37.40; H, 5.90; N, 17.20.

Complexation of 4 with L-Glu (1:1): A mixture of 4 (0.20 g, 1.28 mmol), L-Glu (0.38 g, $2.56 \mathrm{mmol})$, and water $(8 \mathrm{~mL})$ was heated at $\sim 50{ }^{\circ} \mathrm{C}$. The resulting solution was kept at ca. 4 ${ }^{\circ} \mathrm{C}$ with successive additions of EtOH (small portions up to $16 \mathrm{~mL}$ ), which afforded a white solid (8, $0.38 \mathrm{~g}, 98 \%), \mathrm{mp}=195{ }^{\circ} \mathrm{C},[\alpha]_{\mathrm{D}}=+3.0\left(c=0.007, \mathrm{H}_{2} \mathrm{O}\right)$. Anal. calcd for $\mathrm{C}_{10} \mathrm{H}_{17} \mathrm{~N}_{5} \mathrm{O}_{6} \cdot \mathrm{H}_{2} \mathrm{O}$ : C, 37.38; H, 5.96; N, 21.80; found: C, 36.95; H, 5.90; N, 21.50.

Complexation of 4 with DL-Asp and DL-Glu (1:2:1): A mixture of 4 (0.20 g, $1.28 \mathrm{mmol})$, DL-Asp (0.17 g, $1.28 \mathrm{mmol})$, DL-Glu (0.19 g, $1.28 \mathrm{mmol})$, and water (6 mL) was heated until complete dissolution. Then, it was cooled $\left(4{ }^{\circ} \mathrm{C}\right)$ and $\mathrm{MeOH}$ was added $(4 \mathrm{~mL})$ giving a white solid (9, 0.20 g, 54\%), mp $=149{ }^{\circ} \mathrm{C}$ (dec.). Anal. calcd for $\mathrm{C}_{18} \mathrm{H}_{31} \mathrm{~N}_{7} \mathrm{O}_{14} \cdot 3 \mathrm{H}_{2} \mathrm{O}$ : C, 34.67; H, 5.98; N, 15.72; found: C, 34.61; H, 5.54; N, 15.55.

Complexation of 5 with L-Asp (1:1): A mixture of 5 (0.20 g, 1.15 mmol), L-Asp (0.15 g, $1.15 \mathrm{mmol})$ and water $(4 \mathrm{~mL})$ was heated $\left(\sim 50^{\circ} \mathrm{C}\right)$ until dissolution. It was then cooled at $c a$. $4{ }^{\circ} \mathrm{C}$ adding dropwise $\mathrm{MeOH}$ (up to $8 \mathrm{~mL}$ ), which afforded an initial crop of L-aspartic acid (0.023 g, $0.17 \mathrm{mmol})$. After removal by filtration and subsequent addition of $\mathrm{MeOH}(14 \mathrm{~mL})$, the second crop contained compound $10(0.029 \mathrm{~g}, 12 \%), \mathrm{mp}=183{ }^{\circ} \mathrm{C}\left(\mathrm{dec}\right.$.), $[\alpha]_{\mathrm{D}}=+18.8$ 
$\left(c=0.005, \mathrm{H}_{2} \mathrm{O}\right.$ ). Anal. calcd for $\mathrm{C}_{10} \mathrm{H}_{17} \mathrm{~N}_{3} \mathrm{O}_{8} \cdot \mathrm{H}_{2} \mathrm{O}$ : C, 36.93; H, 5.89; N, 12.92; found: $\mathrm{C}$, 36.63; H, 5.40; N, 12.70 .

Dimerization of amino acids in the presence of compound 4: A mixture of 4 (0.25 g, 1.6 $\mathrm{mmol})$ and the corresponding amino acid $(8.0 \mathrm{mmol})$ was dissolved in water $(20 \mathrm{~mL})$ and heated at $\sim 70{ }^{\circ} \mathrm{C}$ for approximately one month $(670 \mathrm{~h})$. Aliquots were regularly extracted (ranging from $24 \mathrm{~h}$ to one week), diluted to a final concentration of $10 \mathrm{ppm}$, and then subjected to ESI-MS analysis following the procedure described in the Electronic Supplementary Material (ESM, Tables S5 and S6).

\section{Results and discussion}

\section{Formation and structural features of zwitterionic complexes}

As pointed out above the preparation of $\mathbf{4}$ can easily be conducted in water at room temperature from dihydroxyacetone and cyanamide (Saul et al. 2002). The resulting solid exhibits two methylene proton sinnals at $\delta 4.36$ and $4.26 \mathrm{ppm}$, whose diastereotopicity is consistent with a chiral structure. Unfortunately, it crystallizes as racemic compound, not conglomeratic phase, which impedes spontaneous resolution by crystallization. Diastereomeric resolution also failed for this spiranic substance. Homochiral $\mathbf{5}$ was prepared from D-ribose and cyanamide. We observe that, contrary to previous literature reporting its synthesis at basic pH (Borsenberger et al. 2004; Springsteen and Joyce 2004) crystallization of 5 also occurs under essentially neutral conditions ( $\mathrm{pH} \sim 7.0$ ) and mild heating (ca. $40{ }^{\circ} \mathrm{C}$ ) as well.

In order to investigate whether $\mathbf{4}$ does actually interact with amino acids and exert a discriminating effect against the enantiomeric pair, 1:1 mixtures of both substrates in $\mathrm{D}_{2} \mathrm{O}$ solutions (0.06 M each) were monitored by ${ }^{1} \mathrm{H}$ NMR. For comparison, both racemates (DL) and optically active (L-configured) amino acids were evaluated. In some cases the low aqueous solubility of the amino acid or parent heterocycle led to mixtures deviating from an equimolar ratio (molar relationships collected in Tables 1 and 2 were measured by integration). Chemical shift variations $(\Delta \delta)$ refer to differences before and after interactions for a given proton signal: $\mathrm{CH} \alpha\left(\mathrm{H}_{1}\right)$ for the amino acid as well as the diastereotopic methylene protons $\mathrm{H}_{1}$ and $\mathrm{H}_{2}$ of aminoxazoline 4 and the bridged $\mathrm{H}_{1}$ and $\mathrm{H}_{2}$ signals of $\mathbf{5}$. For 
most amino acids (Arg, Phe, Pro, Ala, Gly, Ser, Gln, Lys, His, Thr, or Asn), $\Delta \delta$ values were almost negligible (from 0.01 to $0.07 \mathrm{ppm}$ for all proton resonances). However, dicarboxylic amino acids, such as Asp and Glu, showed significant variations for the oxazoline protons (from 0.22 to $0.47 \mathrm{ppm}$ ) and to a lesser extent for $\mathrm{H}_{1}$ ' protons (see $\mathrm{ESM}$ ). These observations point to interactions of the oxazoline moiety with the amino acid side chain, where the isoureido linkage of the former undergoes protonation, deshielding the vicinal hydrogen atoms, whereas the negative charge of the carboxylate group causes further shielding on the adjacent $\mathrm{H}$-atoms.

Table 1 Proton resonances $(\delta)$ and proton shift variations $(\Delta \delta)$ for compound 4, Asp and Glu, and the resulting zwitterions in $\mathrm{D}_{2} \mathrm{O}$.

\begin{tabular}{|c|c|c|c|c|c|c|c|}
\hline \multirow[b]{2}{*}{ Comp. } & \multicolumn{2}{|c|}{${ }_{4}^{\mathrm{H}_{2}^{\mathrm{H}_{1}}}$} & \multicolumn{2}{|c|}{ 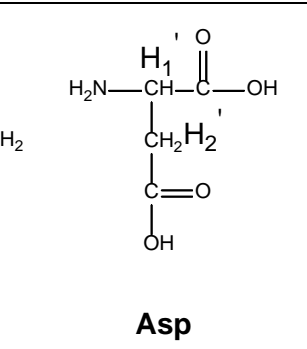 } & 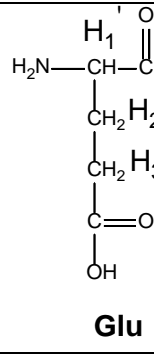 & \multirow[b]{2}{*}{$\mathbf{H}_{3^{\prime} \mathbf{a}}$} & \multirow[b]{2}{*}{$\mathbf{H}_{3^{\prime} \mathbf{b}}$} \\
\hline & $\mathbf{H}_{1}$ & $\mathbf{H}_{2}$ & $\mathbf{H}_{1}{ }^{\prime}$ & $\mathbf{H}_{2} \mathbf{a}$ & $\mathbf{H}_{2^{\prime} \mathbf{b}}$ & & \\
\hline 4 & 4.36 & 4.26 & & & & & \\
\hline DL-Asp & & & 4.06 & 3.02 & 2.94 & & \\
\hline $1: 1^{a}$ & 4.71 & 4.66 & 3.89 & 2.81 & 2.67 & & \\
\hline$\Delta \delta$ & 0.35 & 0.40 & -0.17 & -0.21 & -0.27 & & \\
\hline L-Asp & & & 4.06 & 3.02 & 2.96 & & \\
\hline 1:1 $\mathrm{Mix}^{\mathrm{a}}$ & 4.72 & 4.67 & 3.89 & 2.81 & 2.67 & & \\
\hline$\Delta \delta$ & 0.36 & 0.41 & -0.17 & -0.21 & -0.29 & & \\
\hline DL-Glu & & & 3.80 & 2.14 & 2.14 & 2.54 & 2.54 \\
\hline 1:1 Mix & 4.66 & 4.61 & 3.74 & 2.12 & 2.05 & 2.34 & 2.34 \\
\hline$\Delta \delta$ & 0.30 & 0.35 & -0.06 & -0.02 & -0.09 & -0.20 & -0.20 \\
\hline L-Glu & & & 3.77 & 2.12 & 2.12 & 2.52 & 2.52 \\
\hline 1:1 $\mathbf{M i x}^{\mathrm{a}}$ & 4.72 & 4.68 & 3.75 & 2.12 & 2.06 & 2.37 & 2.36 \\
\hline$\Delta \delta$ & 0.36 & 0.42 & -0.02 & 0.00 & -0.06 & -0.15 & -0.16 \\
\hline
\end{tabular}

${ }^{\mathrm{a} O x a z o l i n e: a m i n o}$ acid ratio determined by proton integration (at $500 \mathrm{MHz}$ ). 
It is obvious that, in strict sense, the term complexation cannot be claimed in the present context, as the aforementioned results are clearly consistent with proton transfer from either the aspartic or glutamic acid side chain to the spiranic fragment of 4 . Such proton transfers could explain the expected effect on the chemical shifts of both substrates, amino acid and heterocycle. Accordingly,they may be solvated in the aqueous environment, thereby preventing complex formation per se. This could therefore be achieved by interactions that overcome the hydration of the binding partners or, alternatively by harnessing solvophobic effects, as demonstrated in anion recognition by peptide-like structures (Kubik 2017). In any case, the generation of zwitterionic aggregates triggered by simple proton transfer would have enabled the stabilization and accumulation of sensitive reagents. This proton transfer will also be noticeable if that interaction between acid and basic groups in reaction partners primarily drives the formation of cocrystals, thereby enhancing the separation process, as we shall discuss later.

\section{Isolation and characterization of solid-state structures}

Crystallization screenings were performed for mixtures of 4 with Asp and Glu. The protocol was extended to other bifunctional amino acids like asparagine (Asn), though without success. Both reaction partners (in 1:1 and 1:2 molar ratios) were dissolved in water at $c a .50^{\circ} \mathrm{C}$. Since no crystallization was observed, dropwise addition of $\mathrm{MeOH}$ or EtOH, caused the precipitation of white solids. Unfortunately most trials were unsuccessful, leading to the selective precipitation of one of the starting materials. Gratifyingly, DL-Asp and LGlu behaved differently and showed conversion to solid phases consistent with their cocrystallization with 4 (details included in the ESM, Table S3).

In addition to spectroscopic characterization, the complex obtained from $\mathbf{4}$ and DL-Asp could be unambiguously elucidated by single-crystal XRD. The solid $\mathbf{6}$ decomposes at 155 ${ }^{\circ} \mathrm{C}$ and had elemental analysis that agrees with the formation of a hydrate derivative $\left(\mathrm{C}_{13} \mathrm{H}_{22} \mathrm{~N}_{6} \mathrm{O}_{10} \cdot 2 \mathrm{H}_{2} \mathrm{O}\right)$, thus pointing to a 1:2:2 (4:DL-Asp: $\left.\mathrm{H}_{2} \mathrm{O}\right)$ stoichiometry. As determined by ${ }^{1} \mathrm{H}$ NMR analysis in $\mathrm{D}_{2} \mathrm{O}$, the 1:2 relationship between 4 and Asp is constant irrespective of the initial ratio of both substrates. This suggests that each amino group of $\mathbf{4}$ participates in hydrogen bonding with the carboxylate group of two different amino acid molecules. This 
would also support the involvement of the adjacent ring nitrogen in bonding, thus reinforcing the chelate structure (Figure 1).

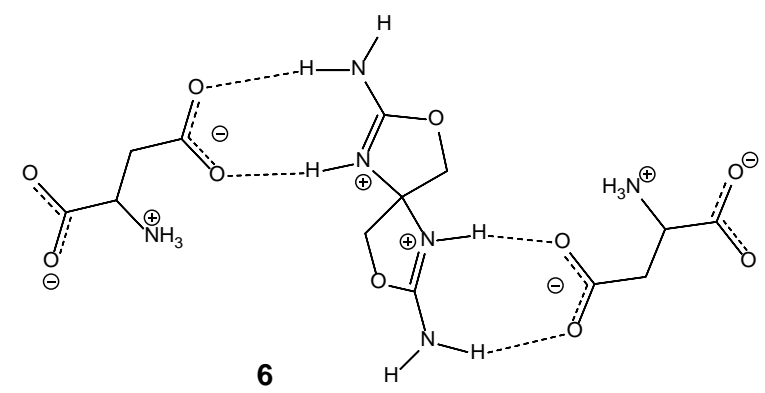

Figure 1 Putative structure showing the complexation of 4 with DL-Asp. Water molecules could also be involved in H-bonding (not shown).

Water uptake can be inferred from the solid-state FT-IR spectrum, which shows broad and intense bands between 3500 and $3000 \mathrm{~cm}^{-1}$ (Figure S15). As mentioned, suitable crystals for X-ray diffraction allowed us to confirm the 3D-arrangement of reaction partners and water molecules in the unit cell, in agreement with the above surmises (Figure 2). On the basis of a racemic amino acid, we also expected to see a centrosymmetric space group, which turned to be true as complex 6 crystallizes in the monoclinic $C 2 / c$ group $(Z=4)$, where amino acid residues of opposite handedness coexist within the unit cell. This structure is similar to that of multicomponent crystals of some amino acids, namely L-Trp, with $N$-heterocyclic carboxylic acids, for which double zwitterions have been recently reported with change in the absolute configuration during cocrystallization (Das and Srivastava 2017). The term zwitterionic cocrystal is usually applied to systems consisting of a zwitterionic compound and a neutral molecule (Aakeröy et al. 2008), which show common features of supramolecular organization and hydrogen bonding (vide infra). Numerous zwitterionic cocrystals involve amino acids as the resulting solids are expected to have enhanced aqueous solubility, a property harnessed in the preparation of pharmaceutical cocrystals for oral delivery (Tilborg et al. 2014; Surov et al. 2018). Likewise, the spirane-amino acid structure 6 resembles that of guanidinium hosts with carboxylate anions (Berger and Schmidtchen 1999; Blondeau et al. 2007), though as noted above, their complexation was reported in aprotic media. 
Table 2 Proton resonances $(\delta)$ and proton shift variations $(\Delta \delta)$ for compound 5, amino acids (Asp, Glu), and the resulting zwitterions in $\mathrm{D}_{2} \mathrm{O}$.

\begin{tabular}{|c|c|c|c|c|c|c|c|c|c|c|}
\hline \multirow[b]{2}{*}{ Comp. } & \multicolumn{3}{|c|}{${ }_{\mathrm{OH}}^{\mathrm{HO}}$} & & $\begin{array}{l}\mathrm{H}_{1}^{\prime} \stackrel{\mathrm{O}}{\|} \\
-\mathrm{CH}-\mathrm{C} \\
\mathrm{CH}_{\mathrm{C}_{2}} \\
\mathrm{C}_{2}=\mathrm{O} \\
\mathrm{O}_{\mathrm{OH}}\end{array}$ & & \multicolumn{2}{|c|}{ 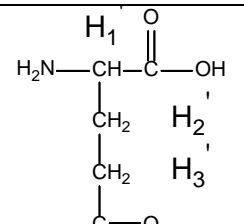 } & \multirow[b]{2}{*}{$\mathbf{H}_{2^{\prime} \mathbf{b}}$} & \multirow[b]{2}{*}{$\mathbf{H}_{3^{\prime}}$} \\
\hline & $\mathbf{H}_{1}$ & $\mathbf{H}_{2}$ & $\mathbf{H}_{3}$ & $\mathbf{H}_{4}$ & $\mathbf{H}_{5 a}$ & $\mathbf{H}_{5 b}$ & $\mathbf{H}_{\mathbf{1}^{\prime}}$ & $\mathbf{H}_{\mathbf{2}^{\prime} \mathbf{a}}$ & & \\
\hline 5 & 5.79 & 4.98 & 4.12 & 3.61 & 3.91 & 3.72 & & & & \\
\hline DL-Asp & & & & & & & 4.06 & 3.02 & 2.96 & \\
\hline 1:1 Mix & 6.05 & 5.45 & 4.29 & 3.87 & 3.92 & 3.74 & 3.95 & 2.84 & 2.73 & \\
\hline$\Delta \delta$ & 0.26 & 0.47 & 0.17 & 0.26 & 0.01 & 0.02 & -0.11 & -0.18 & -0.23 & \\
\hline L-Asp & & & & & & & 4.06 & 3.02 & 2.96 & \\
\hline 1:0.78 $\mathrm{Mix}^{\mathrm{a}}$ & 6.05 & 5.45 & 4.29 & 3.87 & 3.95 & 3.74 & 3.90 & 2.82 & 2.68 & \\
\hline$\Delta \delta$ & 0.22 & 0.47 & 0.17 & 0.26 & 0.04 & 0.02 & -0.16 & -0.20 & -0.28 & \\
\hline DL-Glu & & & & & & & 3.80 & 2.14 & 2.14 & 2.55 \\
\hline 1:1 Mix & 6.05 & 5.45 & 4.29 & 3.74 & 3.95 & 3.86 & 3.76 & 2.13 & 2.07 & 2.38 \\
\hline$\Delta \delta$ & 0.26 & 0.47 & 0.17 & 0.13 & 0.04 & 0.14 & -0.04 & -0.01 & -0.07 & -0.17 \\
\hline L-Glu & & & & & & & 3.77 & 2.12 & 2.12 & 2.52 \\
\hline 1:0.78 $\mathrm{Mix}^{\mathrm{a}}$ & 6.05 & 5.44 & 4.29 & 3.86 & 3.95 & 3.76 & 3.74 & 2.13 & 2.07 & 2.37 \\
\hline$\Delta \delta$ & 0.26 & 0.46 & 0.17 & 0.25 & 0.04 & 0.04 & -0.03 & 0.01 & -0.05 & -0.15 \\
\hline
\end{tabular}

${ }^{\mathrm{a}}$ Oxazoline:amino acid ratio determined by proton integration (at $500 \mathrm{MHz}$ ).

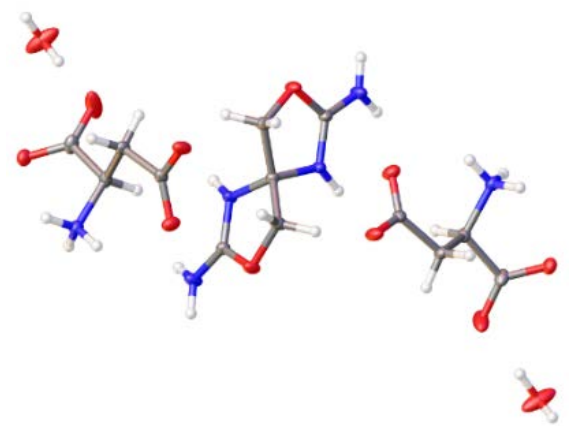

Fig. 2 X-Ray structure of complex 6 as a dihydrate, generated from 4 and DL-Asp. Ellipsoids are drawn at $50 \%$ probability. 
The asymmetric unit of compound $\mathbf{6}$ contains one Asp anion, half a dioxadiaza-spirane dication (on a 2-fold rotation axis) and one water molecule. Asp is in its 'straight' conformation with the torsion angle C4-C5-C6-C7 having a value of $-174.46(10)^{\circ}$ (the alternative bent conformation has torsion angles in the range $c a .50-70^{\circ}$ ). The carboxylate groups are in their resonance form C4-O2 = 1.2726(16) $\AA$, C4-O3 = 1.2441(15) $\AA$, a significant difference of $0.0285(22) \AA$ and C7-O4 = 1.2454(18) $\AA, \mathrm{C} 7-\mathrm{O} 5=1.2513(16) \AA$, which are the same within error. Each five-membered ring of the spirane is in a twisted confirmation with Cremer-Pople puckering parameters of $\mathrm{Q}(2)=0.1760(12) \AA$ and Phi $(2)=349.2(4)^{\circ}$ (Cremer and Pople 1975). The angle between the least squares planes is $87.08(8)^{\circ}$. The supramolecular structure is dominated by hydrogen bonding (all heteroatom hydrogens were clearly located in the difference map and freely refined) ultimately forming a 3D network. Figure 3 shows the unique hydrogen bond interactions with associated atom numbering, while Figure 5 shows the 3D network as most clearly seen viewed down the $b$ axis.

In the asymmetric unit there are five acceptors (carboxylate groups and the water) and four donors with eight hydrogens ( $\mathrm{N}-\mathrm{H}, \mathrm{N}-\mathrm{H} 2, \mathrm{~N}-\mathrm{H} 3$ and $\mathrm{H}_{2} \mathrm{O}$ ), all are involved in hydrogen bond interactions. Taking the spirane as a central motif (Figure 4) there are strong interactions to one of the carboxylate groups of the aspartate anion on either side described with the wellestablished graph-set terminology (Etter et al. 1990) as R2,2(8). The carboxylate at the other end of the anion makes hydrogen bonds to two water molecules and through a centre of symmetry forms a ring, R4,4,(12), with a symmetry related anion. A further ring motif, $\mathrm{R} 4,4(24)$, is formed linking two spirane molecules through $\mathrm{O} 2$ of the carboxylate. The propagation, through the symmetry of the space-group, of these hydrogen bonded rings complete the 3D network. The corresponding symmetry codes (Hall and McMahon 2006) are included in Figures 3 and 4. 


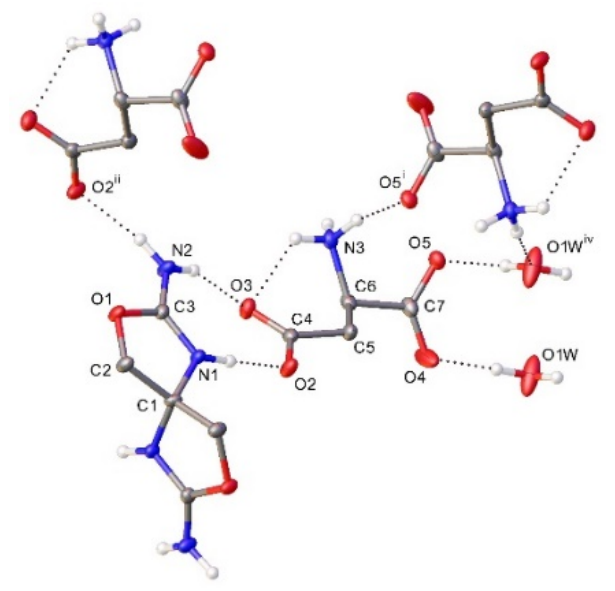

Fig. 3 Unique hydrogen bond interactions. Asymmetric unit and selected symmetry equivalent positions labelled, thermal ellipsoids drawn at the 50\% probability level. Symmetry codes: (i) 3/2-x,1/2+y,3/2-z; (ii) +x,-y,1/2+z; (iv) 3/2-x,3/2-y,1-z.

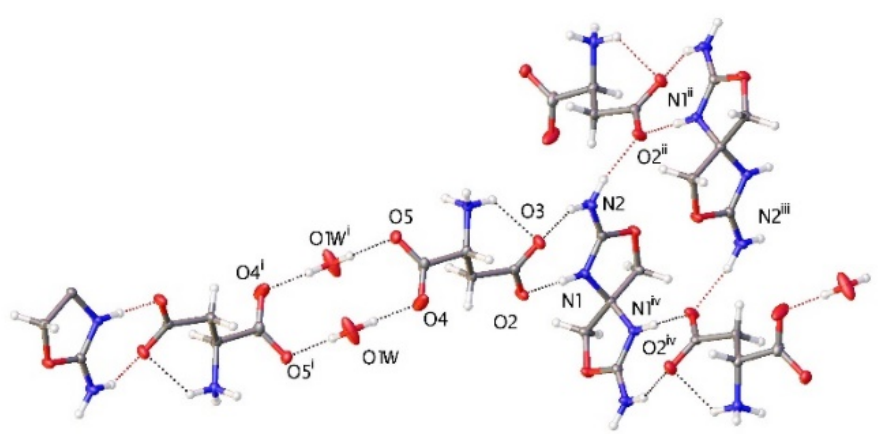

Fig. 4 The R4,4,(12), R2,2(8) and R4,4(24) ring motifs; symmetry codes: (i) 3/2-x, 3/2-y, 1-z; (ii) +x, -y, 1/2+z; (iii) 1-x, 1-y, 2-z; (iv) 1-x, +y, 3/2-z. 


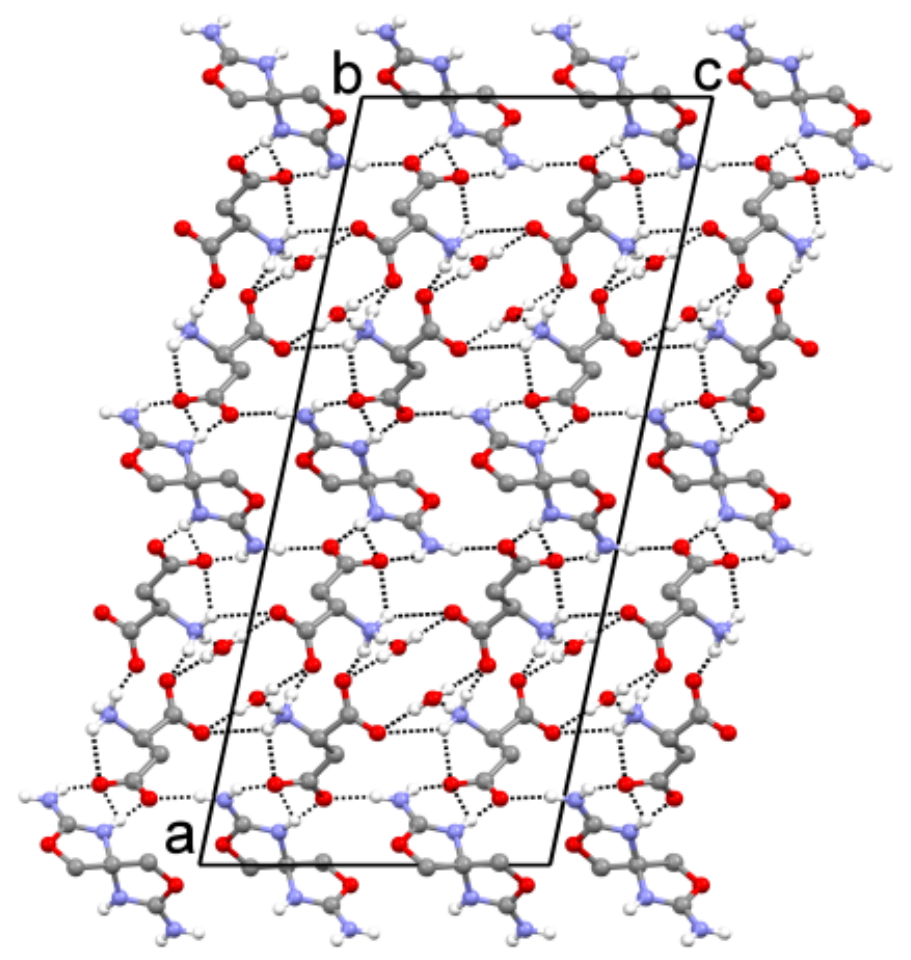

Fig. 5 View of the hydrogen bonding network of $\mathbf{6}$ along the $b$-axis.

For comparative purposes with Tables 1 and 2 where proton shift variations were measured for 1:1 mixtures, data gathered in Table 3 show ${ }^{1} \mathrm{H}$ NMR shifts in $\mathrm{D}_{2} \mathrm{O}$ for 6 possessing a 1:2 stoichiometry (Figure $\mathrm{S} 16$ ). The $\mathrm{H}_{1}$ and $\mathrm{H}_{2}$ signals of spiranic aminoxazoline exhibit larger $\Delta \delta$ variations than those of Tables 1 and 2 . Alternatively, as expected for an increase in amino acid concentration, its proton signals are likewise less shielded in complex 6. As emphasized earlier, the ionic species arising from $\mathrm{H}$-transfer may be perfectly solvated in the aqueous solution.

Table 3. Proton resonances $(\delta)$ and proton shift variations $(\Delta \delta)$ for complex 6 (1:2 spirane:amino acid ratio) relative to 4 and DL-Asp in $\mathrm{D}_{2} \mathrm{O}$ solution.

\begin{tabular}{cccccc}
\hline Comp- & $\mathbf{H}_{\mathbf{1}}$ & $\mathbf{H}_{\mathbf{2}}$ & $\mathbf{H}_{\mathbf{1}^{\prime}}$ & $\mathbf{H}_{\mathbf{2}^{\prime} \mathbf{a}}$ & $\mathbf{H}_{\mathbf{2}^{\prime} \mathbf{b}}$ \\
\hline $\mathbf{6}$ & 4.91 & 4.85 & 3.92 & 2.85 & 2.73 \\
$\mathbf{4}$ & 4.37 & 4.26 & & & \\
$\mathbf{D L}-\mathbf{A s p}$ & & & 4.06 & 3.02 & 2.96 \\
$\boldsymbol{\Delta} \boldsymbol{\delta}$ & 0.54 & 0.59 & -0.14 & -0.17 & -0.23 \\
\hline
\end{tabular}


Under similar experimental conditions, L-Asp failed to afford a cocrystal. Notably, the situation was exactly permuted for glutamic acid as a distinctive solid phase could only be obtained for the L-enantiomer. Starting from 1:2 (4:L-Glu) ratios, two different solids were isolated depending on the antisolvent employed for precipitation, either $\mathrm{MeOH}$ or EtOH. While solid-state FT-IR spectra were essentially identical for both complexes (Figures S17 and S18), ${ }^{1} \mathrm{H}$ NMR spectra recorded in $\mathrm{D}_{2} \mathrm{O}$ revealed two different stoichiometries (Figures S19 and S20). Complex 7, isolated by adding $\mathrm{MeOH}$ as precipitating agent, showed signals at $\delta=4.34$ ( $\mathrm{H}_{2}$ of the spiranic unit, two equivalent protons) and $\delta=3.73 \mathrm{ppm}$ in ca. 1:2 ratio, consistent with the formation of a 1:2 (4:L-Glu) complex, whereas integration of the same signals in complex 8, isolated by adding EtOH as antisolvent, gave rise to $\sim 1: 1$ relationship. Again, Figure 6 displays putative structures for such complexes (see ESM: Table S1 for Hshift variations observed for $\mathbf{7}$ and $\mathbf{8}$ in $\mathrm{D}_{2} \mathrm{O}$ ). Only minor differences in chemical shifts could be observed and, as noted above for rac-Asp, the most significant changes are detected for the methylene group ( $\mathrm{H}_{3}$, signal) at the side chain, thus reflecting the interaction of that carboxylate group, rather than that of $\mathrm{C} \alpha$, with the heterocyclic moiety. Elemental analyses measured for $\mathbf{7}$ and $\mathbf{8}$ were consistent with the formation of dihydrate and monohydrate phases, respectively. They had in addition different, yet close, melting points and optical rotations (see experimental procedures).

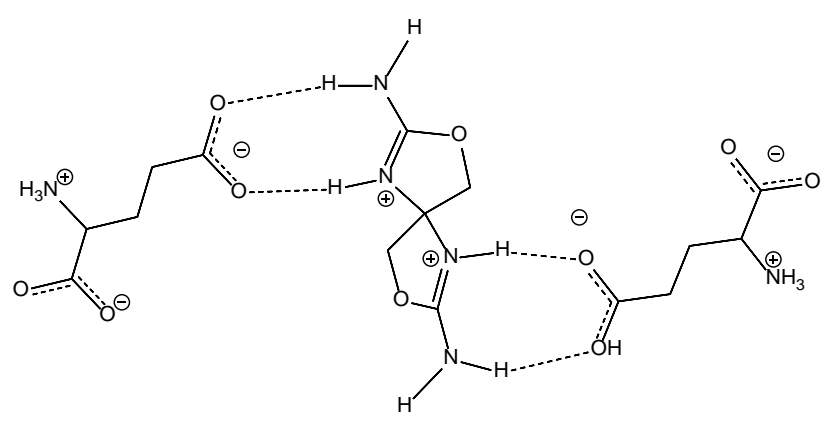

7

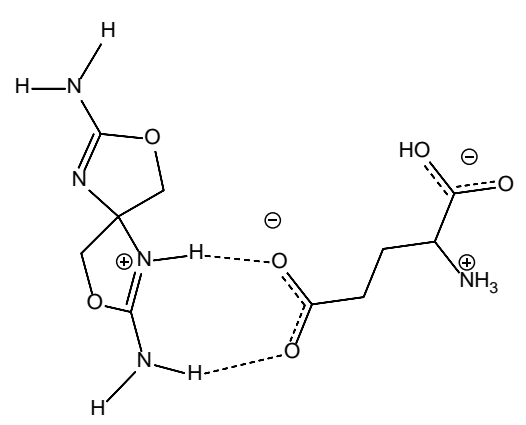

8

Fig. 6 Possible complexes $\mathbf{7}$ and $\mathbf{8}$ showing the coordination of $\mathbf{4}$ with L-Glu through carboxylate groups of the side chain. Water molecules could also be involved in H-bonding.

Given the bidentate character of $\mathbf{4}$, we wondered if it might be possible to form the aminoxazoline derivative to two amino acids of mixed handedness. Accordingly, the 
assembly of 4 with DL-Asp and DL-Glu was investigated using equimolar amounts. Additon of $\mathrm{MeOH}$ gare a white precipitate whose spectral features were different from those of the starting materials (see ESM). The ${ }^{1} \mathrm{H}$ NMR spectrum of the resulting complex (9) in $\mathrm{D}_{2} \mathrm{O}$ shows clearly the coexistence of the three species (Figure S22). Surprisingly, signal integrations unravels a ratio between the aminoxazoline and both amino acids that mismatches the initial stoichiometry, as the amount of Asp approximately doubles that of the others, giving rise to a 1:2:1 (4:DL-Asp:DL-Glu) complex. No crystals suitable for X-ray diffraction could be obtained. Elemental analysis agreed with formation of a trihydrate, where water molecules might also stabilize a cage-like suprastructure through multiple hydrogen bonds. The solid-state FT-IR spectrum (Figure S21) showed broad and intense peaks between 3500 and $3000 \mathrm{~cm}^{-1}$ accounting for the existence of bound $\mathrm{OH}$ bonds. Proton shifts collected in Table S2 (ESM) unveil once again the most salient interactions involving 4 with amino acids. The spiranic protons undergo a strong deshielding of $\sim 0.6 \mathrm{ppm}$, which counterbalances the shielding effect on the amino acid units, especially for aspartic acid. The effect is also more pronounced on the hydrogen atoms of the side chain, thus pointing to prevalent coordination of the heterocycle with a terminal carboxylate group. Figure 7 shows a scheme accounting for the triple interaction of $\mathbf{4}$ with two molecules of Asp and one fragment of Glu.

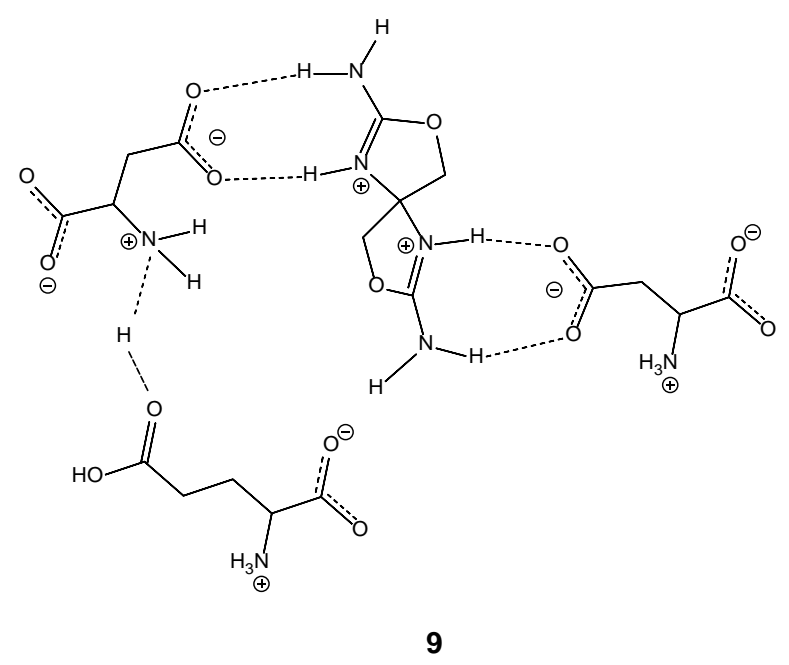

Fig. 7 Schematic proposal for the structure of complex 9 generated from aminoxazoline 4 with aspartic and glutamic acids. Water molecules that should be present in the coordinating sphere have been omitted for clarity. 
Unlike 4, compound 5 did not complex amino acids readily. Numerous failed attempts with Asp, Glu, and Asn led to precipitation of one or both parent materials. The sole exception was L-Asp, which coordinated with 5 in equimolar amounts affording a white solid in $12 \%$ yield from aqueous solution after successive additions of $\mathrm{MeOH}$ as antisolvent.

${ }^{1} \mathrm{H}$ NMR peak integration suggests formation of a 1:1 complex for 5 and L-Asp (Figure S24). As expected the most deshielded signals were the bridged protons of the ribo-oxazoline bicycle $(\Delta \delta=0.44$ and $0.23 \mathrm{ppm})$, whereas minor shielding was observed for $\mathrm{H} \alpha(\Delta \delta=-0.15$ ppm) and diastereotopic $\mathrm{CH}_{2}$ protons $(\Delta \delta=-0.18$ and $-0.25 \mathrm{ppm})$ of the side chain. It seems reasonable to assume that the resulting complex (10) adopts a similar interaction to that of preceding solids involving the terminal carboxylate group and the aminoxazoline skeleton (Figure 8).

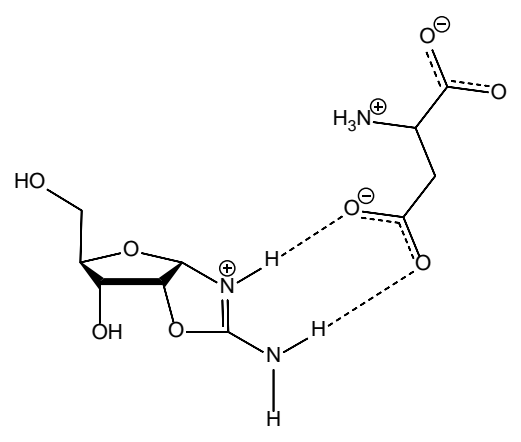

10

Fig. 8: Possible interactions of the complex of L-Asp with 5.

\section{Geometry and stability: computation-aided models}

To further assess the complexation of amino acids with $\mathbf{4}$, the energy-minimized structures of some complexes have been calculated by DFT calculations at the M06-2X/6-31+G(d) level (Zhao and Truhlar 2008), (Ditchfield et al. 1971; Hariharan and Pople 1973; Gordon 1980; Francl et al. 1982) and modelling solvent effects (in water) by means of the continuum SMD model, (Marenich et al. 2009a; Marenich et al. 2009b; Ribeiro et al. 2010; Halim et al. 2010; Saielli 2010), as implemented in the Gaussian suite of programs (Frisch, M J et al. 2009).

Both 1:1 and 1:2 aminoxazoline (4):amino acid complexes were computed, taking also into account for bifunctional amino acids the two possible coordination modes, i.e. either involving the carboxylate group adjacent to $\mathrm{C} \alpha$ (mode $a$ ) or the carboxylate group at the side 
chain (mode $b$ ) to ascertain the influence of the latter. Figures 9 and 10 show the resulting optimized structures for such complexes. Energy data are shown in Tables 4 and 5.

Although enthalpies for 1:1 complexes are thermodynamically favorable, the Gibbs energies are invariably positive as a result of the decreasing entropy upon complexation. Those values decrease (up to $c a .3 \mathrm{kcal} \cdot \mathrm{mol}^{-1}$ ) for Asp and Glu acids which exhibit an intramolecular hydrogen bond. That interaction would also mimic coordination to water molecules (bearing in mind that the SMD method does not include explicit interaction with discrete water molecules, but merely simulates the solvation cage). For Glu, calculations predict a greater stability of the $b$-mode involving coordination to the side chain, the latter participating in non-covalent bonding with the aminoxazoline moiety. This result clearly mirrors the structural arrangement observed in the crystalline phase. Likewise, free energies are unfavorable for 1:2 complexes.

\section{On the catalytic role of aminoxazolines: a computational screening}

When samples of Gly, Ala, or rac-Phe were left in neutral aqueous solution in the presence of 4 with prolonged heating for one week, and the mixture was then checked by mass spectra (MS) analysis (see ESM for details), peaks with $\mathrm{m} / \mathrm{z}$ data consistent with linear or cyclic dipeptides (diketopiperazines, DKP) emerged. The accidental discovery prompted us to investigate theoretically how feasible that dimerization is. 

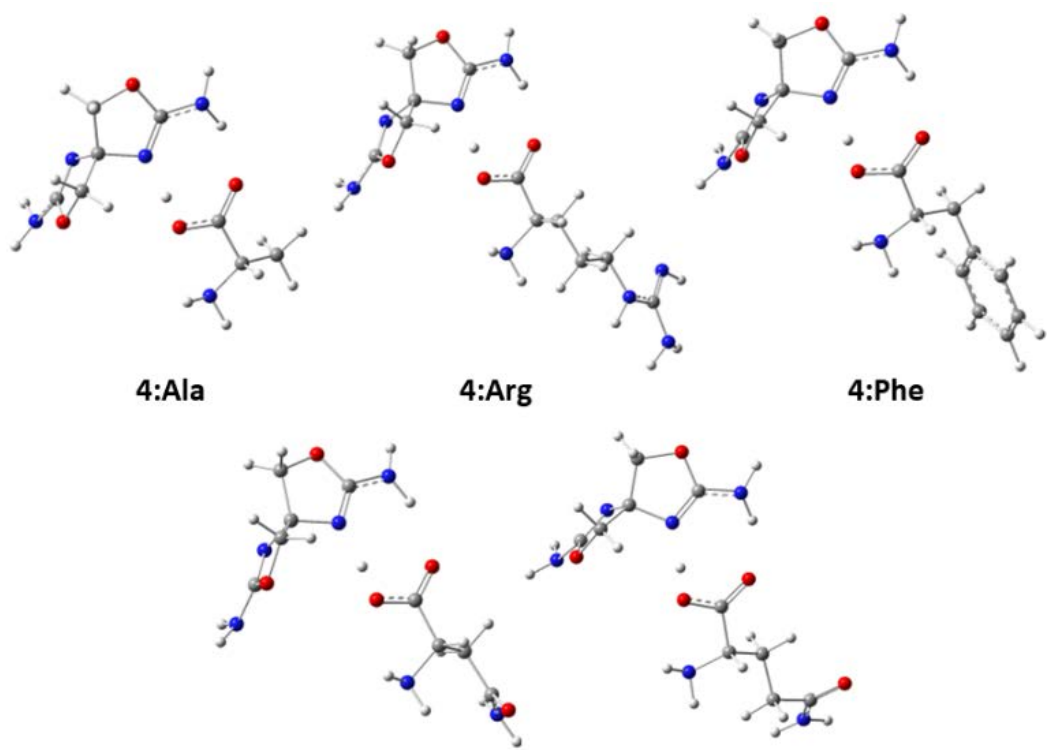

4:Asn

4:GIn
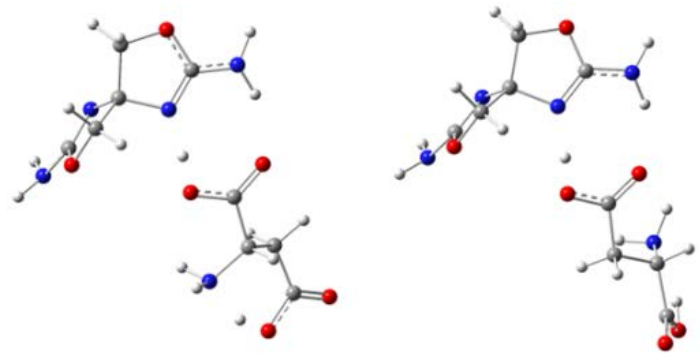

4:Asp ( $a$-mode)

4:Asp (b-mode)

Fig. 9 Energy-minimized structures obtained for 1:1 (4:amino acid) complexes at the M06-2X/6$31+G(d)$ level of theory, including solvent effects in water (SMD).

Table 4. Stabilization energies (in $\mathrm{kcal} \cdot \mathrm{mol}^{-1}$ ) for $1: 1$ aminoxazoline (4):amino acid complexes.

\begin{tabular}{cccc}
\hline Amino acid & $\boldsymbol{\Delta}$ & $\boldsymbol{\Delta}$ & $\boldsymbol{\Delta} \boldsymbol{G}$ \\
\hline Ala & -0.21 & -1.27 & 9.26 \\
Arg & -0.52 & -1.55 & 9.90 \\
Asn & -0.29 & -1.29 & 9.67 \\
Asp ( $a$-mode) & -4.91 & -6.30 & 6.29 \\
Asp (b-mode) & -3.47 & -4.12 & 7.90 \\
Gln & -0.77 & -1.64 & 9.52 \\
Glu ( $a$-mode) & -0.96 & -1.82 & 9.87 \\
Glu (b-mode) & -3.66 & -4.63 & 6.53 \\
Phe & -0.74 & -1.47 & 10.94 \\
\hline
\end{tabular}


The spiro compound $\mathbf{4}$ adopts a relatively rigid bowl-shaped structure whose nitrogen atoms are capable of interacting with amino acid carboxyl groups and may bring about a subsequent dimerization reaction. Compound $\mathbf{4}$, obtained from dihydroxyacetone and cyanamide, can be regarded as a masked surrogate of the latter. The condensing effect of cyanamide favoring the formation of dipeptides from a few amino acids was reported by Hawker and Oró in the early 1980s (Hawker and Oró 1981). Previously, Calvin and coworkers had suggested the use of cyanamide as activating/condensing agent for other biomolecules, although the group was unable to achieve the reaction of adenine and ribose in the presence of cyanamide (Steinman et al. 1964). Recently, dipeptides and diketopiperazines were detected during the incubation of amino acid solutions with cyanamide or dicyanamide in acid (Parker et al. 2014). The prebiotic generation of peptides challenging and numerous strategies thought to be prebiotically plausible have been postulated (Plasson et al. 2004; Pascal et al. 2005; Danger et al. 2012; Weissbuch et al. 2009; Weissbuch et al. 2011; Rode and Schwendinger 1990; Rode 1999; Reiner et al. 2006). 

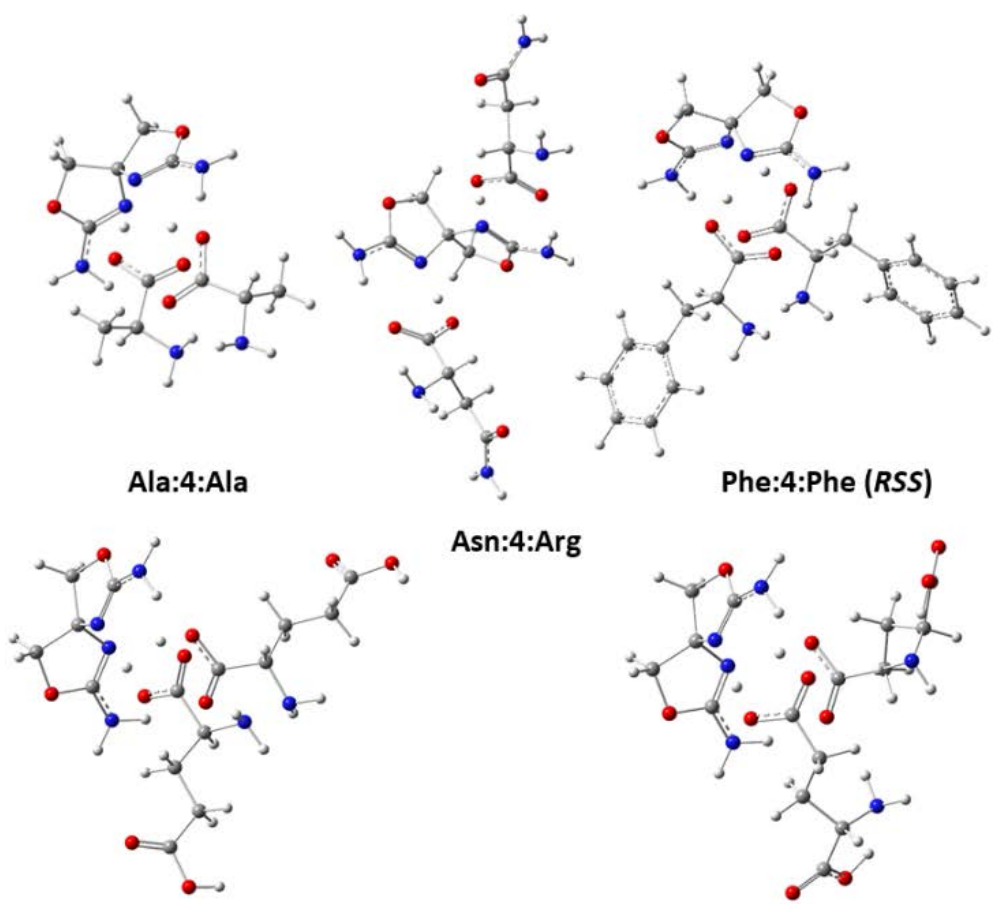

Asn:4:Arg

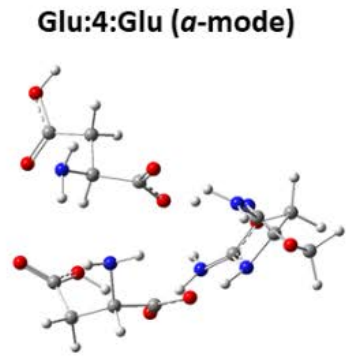

4:Asp ( $a$-mode)

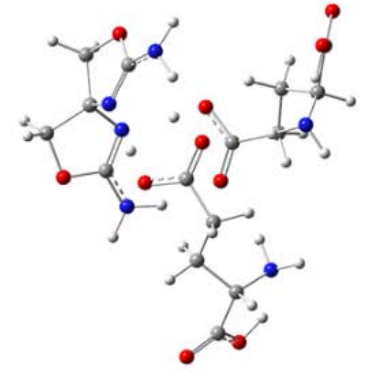

Glu:4:Glu (b-mode)

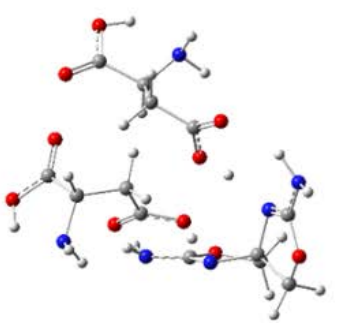

4:Asp (b-mode)

Fig. 10 Energy-minimized structures obtained for 1:2 (4:amino acid) complexes at the M06-2X/6$31+G(d)$ level of theory, including solvent effects in water (SMD). 
Table 5. Stabilization energies (in $\mathrm{kcal} \cdot \mathrm{mol}^{-1}$ ) for 1:2 aminoxazoline (4):amino acid complexes.

\begin{tabular}{cccc}
\hline Amino acid & $\boldsymbol{\Delta}$ & $\boldsymbol{\Delta H}$ & $\boldsymbol{\Delta}$ \\
\hline Ala & -6.66 & -7.94 & 16.80 \\
Asn & -1.49 & -2.42 & 19.70 \\
Asp (a-mode) & -12.41 & -12.44 & 14.19 \\
Asp (b-mode) & -11.11 & -11.87 & 13.65 \\
Glu (a-mode) & -4.78 & -5.54 & 19.30 \\
Glu (b-mode) & -12.24 & -13.59 & 12.63 \\
Phe (RSS) & -8.45 & -9.17 & 17.71 \\
\hline
\end{tabular}

${ }^{\mathrm{a}}$ For this amino acid, thermodynamic data of its complex refer to the (RSS)-configured diastereomer, which shows the highest stability (See next section for a computational rationale).

Scheme 3 shows the dimerization step which, if promoted by $\mathbf{4}$, should occur via a ternary complex stabilized by electrostatic interactions and leading ultimately to dipeptides after intermolecular attack by another amino acid unit. Mass spectra revealed the formation of low-intensity peaks ( $<2 \%$ ), visible after $~ 100$-h incubations, whose mass-to-charge values correspond to Gly-Gly and Phe-Phe. For Ala samples, peaks of higher intensity (up to 6\%), consistent with formation of Ala-Ala were detected after ca. 330 h. Remarkably, those peaks could not be identified in the absence of 4 . To further corroborate the formation of the dipeptide, mass spectra were collected for reaction aliquots along with genuine samples of Phe and Phe-Phe at different voltages $(60,80$ and $120 \mathrm{~V})$ giving rise to $\Delta m / z$ less than 0.01 in all cases among the peaks in question. The intensity of Phe-Phe peaks increased as the reaction progressed, especially for samples measured at $60 \mathrm{~V}$. After prolonged heating (ca. $650 \mathrm{~h}$ ), a peak of low intensity and $\mathrm{m} / \mathrm{z}=295.14 \mathrm{Da}[\mathrm{M}-\mathrm{H}]^{+}$emerges, which can be attributed to the corresponding DKP. That peak was not observed in the absence of $\mathbf{4}$. In the cases of Gly-Gly and Ala-Ala, such dipeptides were better observed through ESI-MS experiments at $80 \mathrm{~V}$. 

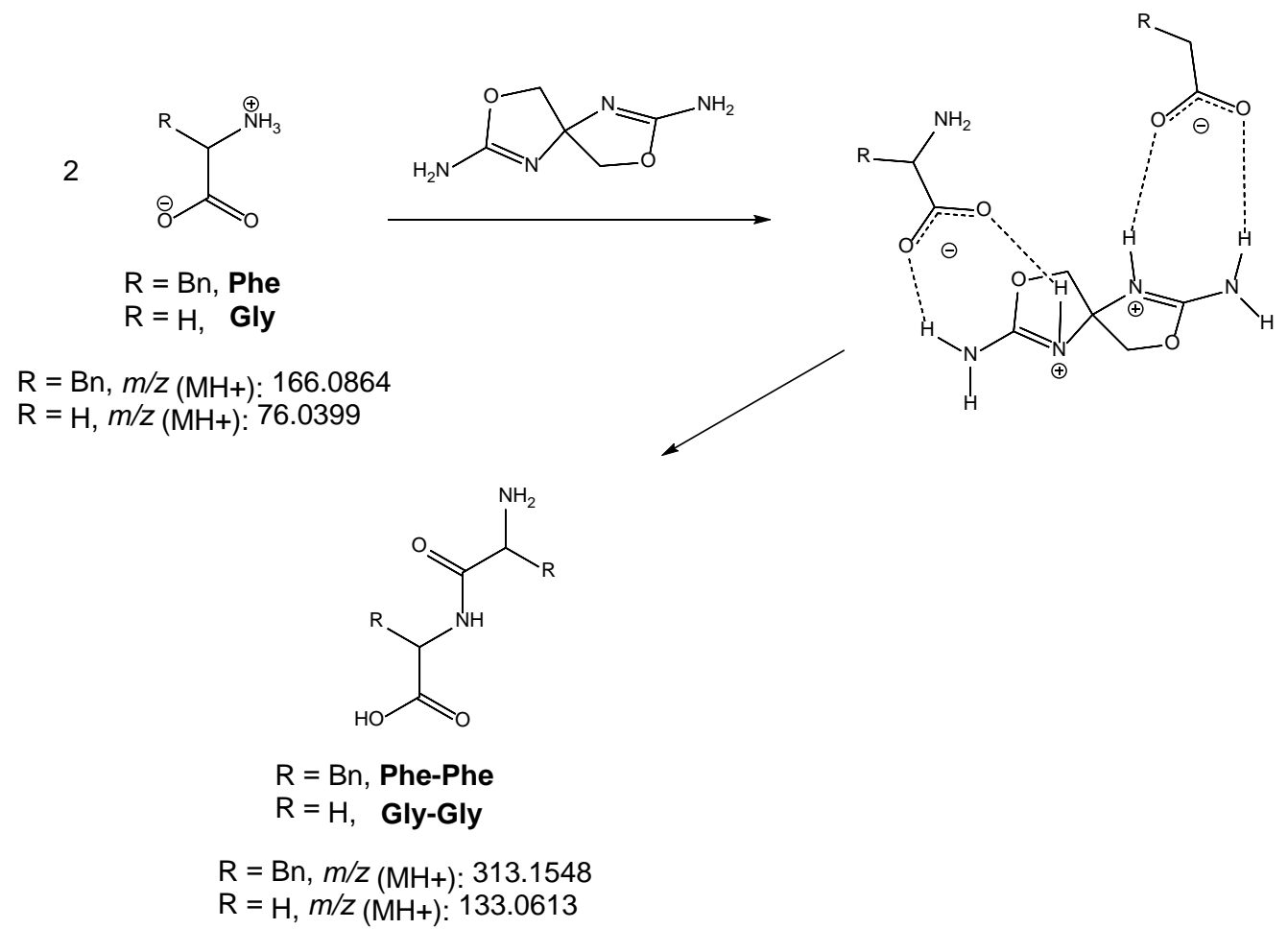

Scheme 3. Reaction scheme for dipeptide formation from Gly and Phe in the presence of $\mathbf{4}$ in water, via the intermediacy of a complex assembled through electrostatic interactions.

Such results are rather disappointing in synthetic terms, even though primeval peptides would have likely been generated in tiny amounts by multiple mechanisms. We wondered whether amino acids other than Gly, Ala, and Phe, especially Asp and Glu, would eventually produce peptides in the presence of $\mathbf{4}$, which were unsuccessful. For Glu, peaks with $\mathrm{m} / \mathrm{z}=$ 259.0930 and 277.1036 Da most likely correspond to dimeric structures. The peak at $\mathrm{m} / \mathrm{z}=$ 259 is consistent with the DKP derivative, but also with a hybrid acyclic-cyclic structure, whereas the peak at $m / z=277$ may include dipeptides involving the two carboxyl groups. As mentioned, an in-silico analysis could be instrumental in elucidating the factors accounting for the formation of Gly-Gly and Phe-Phe in the presence of $\mathbf{4}$ (vide infra), as aqueous solutions of those amino acids alone did not show evidence of dimerization. The choice of Gly and Phe obeys to their representative character as non-aromatic and aromatic amino acids, respectively. On the other hand, the lack of observable coupling for Asp and Glu may be ascribed to the strongest interaction of the aminoxazoline moiety with the distal carboxylate groups (vide supra: Table 5). That interaction also hampers dimerization, as the charged nitrogen atom at the $\alpha$-carbon lacks enough nucleophilicity in aqueous medium. 
The pKas of Gly and Phe in water prevent their amino groups from acting as nucleophile as well. However, the experimental evidence accounting for the formation of Gly-Gly and Phe-Phe does actually suggests a role for the aminoxazole as promoter, which should remove a hydrogen from the ammonium groups, leading to a complex CI (Figure 11) free amino groups could then be engaged in nucleophilic attack. That complex brings the two amino acid units in close proximity to allow their assembly in a peptide bond. Figure 11 depicts this catalytic scheme, where the first step involves the association of two molecules of the amino acid giving rise to $\mathbf{C I}$, followed by intramolecular peptide bond formation. This sequence affords a second complex (CII), from which the dipeptide separates, enabling the heterocycle to initiate another catalytic cycle. 


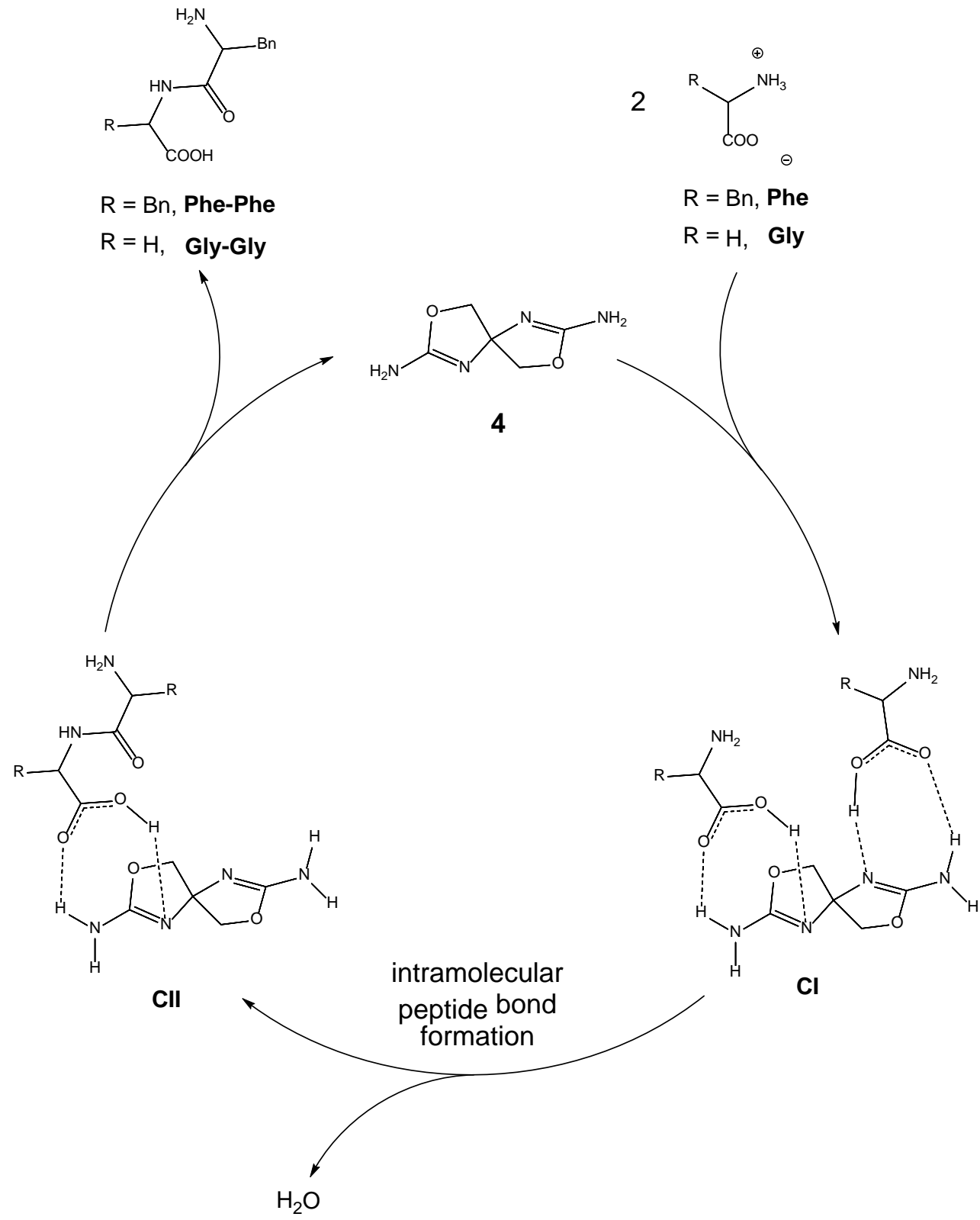

Fig. 11 Catalytic cycle proposed for the dimerization of Gly and Phe in the presence of $\mathbf{4}$ as catalyst.

We have studied the complete reaction pathway yielding Gly-Gly from the initial complex CI $_{\text {Gly }}$ at the M06-2X/6-31+G(d) level of theory in water (SMD). Figure 12 shows the reaction pathways leading to Gly-Gly, whose initial step involves the generation of $\mathbf{C I}_{\mathbf{G l y}}$ and the subsequent first saddle point (TS1Gly), which corresponds to the nucleophilic attack of the amino group to the carboxylic carbon of the other Gly unit. The intermediate Int1Gly, leads then to a second intermediate (Int2Gly) through a second saddle point (TS2Gly). The latter corresponds to proton transfer from the new ammonium group formed. The slightly higher 
relative free energy of Int2 $\mathbf{G l y}$ relative to $\mathbf{T S} \mathbf{2}_{\mathbf{G l y}}$ can be ascribed to their almost identical geometries, which translates into a flat energy profile (see ESM for full energy data). In the last step, which is the rate-determining step (TS3Gy), the newly generated tetrahedral carbon evolves into the amide bond where the hydroxyl plays the role of leaving group. This abstracts the hydrogen atom of the ammonium group of spirane $\mathbf{4}$ in a concerted fashion, thus liberating a water molecule. The second complex CIIGly dissociates into Gly-Gly and spirane 4, which is then available for a new catalytic cycle.

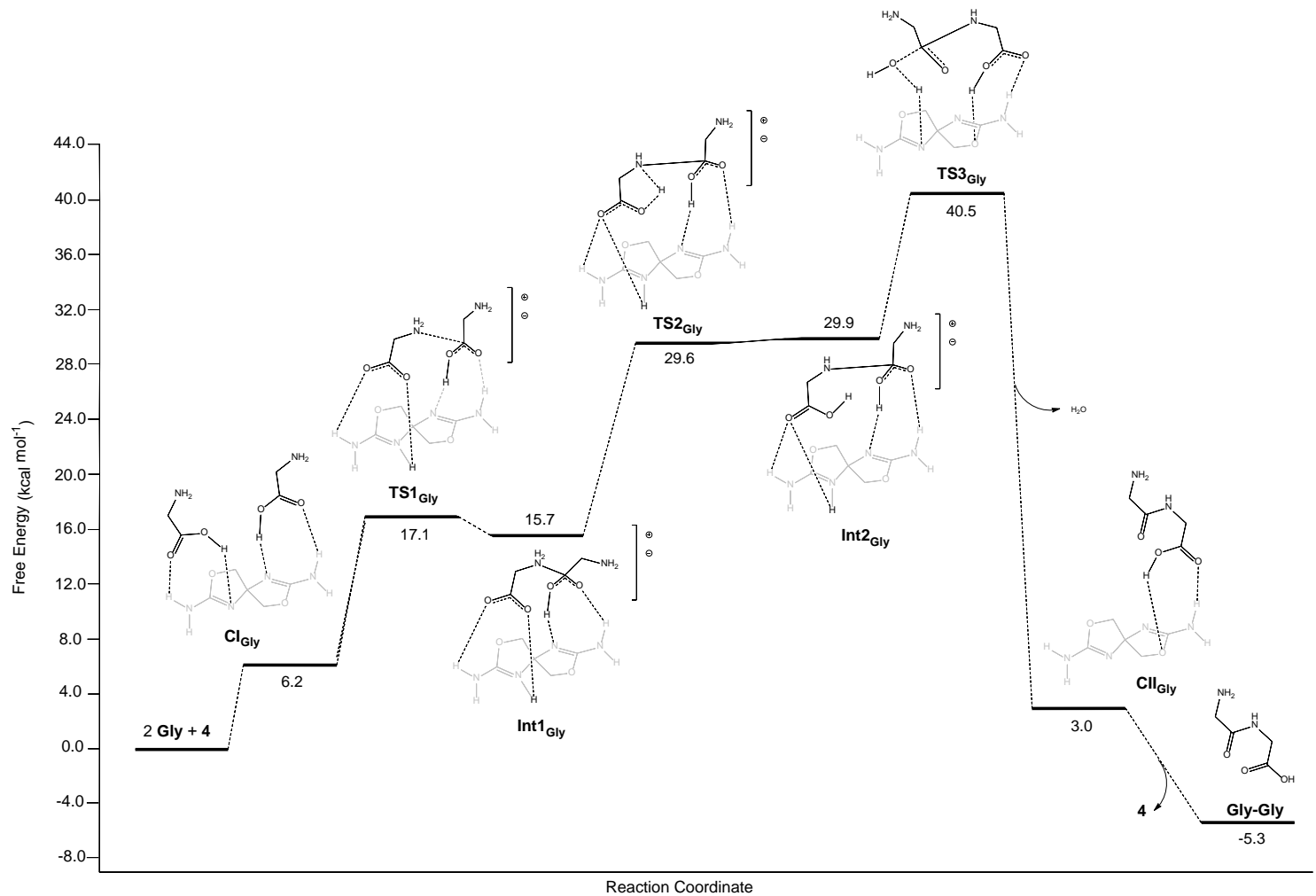

Fig. 12. Reaction pathways for peptide-bond formation between two glycine residues (Gly) catalyzed by spirane $\mathbf{4}$. Free energy differences with respect to Gly and $\mathbf{4}$ are given in $\mathrm{kcal} \mathrm{mol}^{-1}$ at the M062X/6-31+G(d) in water (SMD).

Since Gly is achiral information and the formation of Phe-Phe was also observed by mass spectrometry, we also simulated the reaction pathway leading to Phe-Phe in the presence of 4. Here the chiral nature of the amino acid was taken into account. The $R$ configuration of spirane 4 was arbitrarily chosen in order to ascertain whether an enantiomerically pure sample of the spiranic derivative would still exert chiral selection during the formation of the 
dimer. Accordingly, we computed all the reaction channels starting from the four diastereomers of the initial complex $\mathbf{C I}$, i.e. $R R R, R R S, R S R$ and $R S S$. For clarity, the first configuration refers to the chiral axis of the spiranic compound while the second and third labels allude to the stereogenic atoms of Phe residues. Figure 13 shows the energy landscape (barriers are given in Gibbs energies) leading to chiral Phe-Phe (i.e. $R R, S S, R S$ and $S R$ configurations). Mechanisms were identical to those of Gly, albeit the benzyl group slightly increases the energy gaps of some stationary points, particularly TS2Phe and Int2Phe. For an $(R)$-configured spirane, the most favored pathway yields the RSS-configured product, whose rate-determining step corresponds to the second saddle point $\left[\Delta G^{\ddagger}(\right.$ TS2Pherss $)=51.2 \mathrm{kcal}$ $\left.\mathrm{mol}^{-1}\right]$. This happens for the $R R S$ path as well $\left[\Delta G^{\ddagger}(\mathbf{T S} 2 \mathrm{PheRRS})=52.1 \mathrm{kcal} \mathrm{mol}^{-1}\right]$, while for the $R R R$ and $R S R$ pathways is the third one $\left[\Delta G^{\ddagger}\left(\mathbf{T S}_{\mathbf{P h e} R R R}\right)=52.7\right.$ and $\Delta G^{\ddagger}\left(\mathbf{T S}_{\mathbf{P h e} R \boldsymbol{R} R}\right)=$ $55.0 \mathrm{kcal} \mathrm{mol}^{-1}$ respectively). Although the difference in energy barriers lie in a few $\mathrm{kcal} \mathrm{mol}^{-}$ 1 , the preference toward the homochiral $(S, S)$-dipeptide is noteworthy. The imbalance between homochiral and heterochiral aggregation, favoring the former, has also been observed for other amino acid clusters, for which an entropic advantage has been invoked. (Julian et al. 2005) 


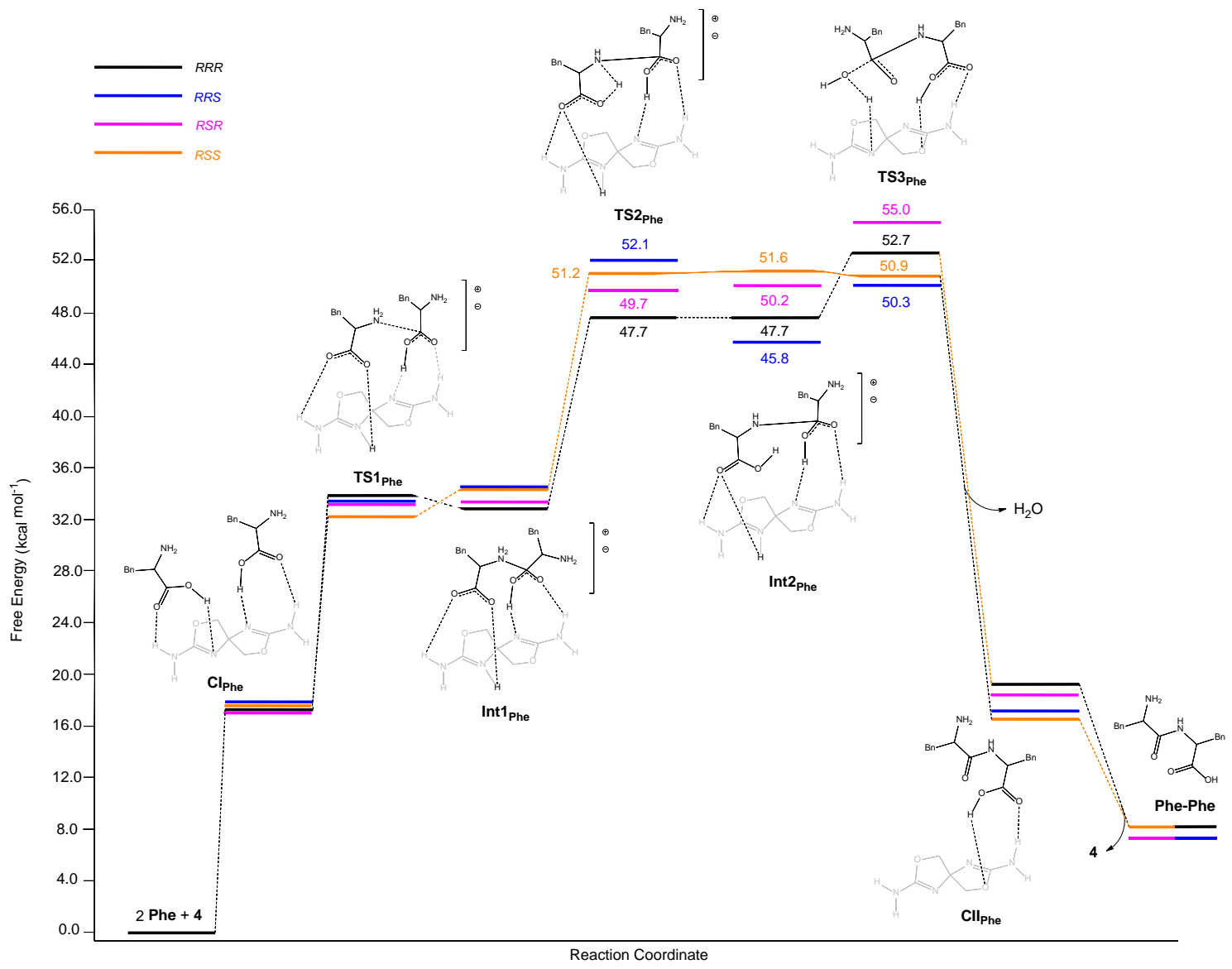

Fig. 13. Reaction pathways for the formation of peptide bonds between two phenylalanine residues (Phe) catalyzed by spirane 4 . Free energy differences are given with respect to Phe and $\mathbf{4}$ in $\mathrm{kcal} \mathrm{mol}^{-}$ ${ }^{1}$ at the M06-2X/6-31+G(d) in water (SMD).

\section{Conclusions}

Aminoxazolines such as 4 , which can be readily generated from cyanamide and dihydroxyacetone, can serve as sequestrating agents for amino acids, with strong interactions for dicarboxylic derivatives such as Glu and Asp. Although ${ }^{1} \mathrm{H}$ NMR data in solution provide some support, interaction-induced shifts due to proton transfer show small variations relative to unbound substrates, with the exception of bifunctional amino acids such as Glu and Asp, for which distinctive solid phases related to cocrystal formation could be isolated. The complex involving two molecules of Asp (as racemate) coordinated through the side carboxylate to the isoureido moiety of $\mathbf{4}$ could be elucidated by X-ray diffractometry. DFT calculations indicate that, despite unfavorable free energies owing to entropic loss after coordination in solution, both Glu and Asp exhibit less positive $\Delta G$ values when they 
coordinate to $\mathbf{4}$ through their carboxylate side chain. Optimized structures also reveal that aminoxazole derivatives are capable of holding the amino acids together, which is now of interest in prebiotic mechanisms of selection and accumulation. In peripheral observations, formation of dipeptides in an aqueous soup containing 4 and Gly, Ala, or Phe could be inferred with confidence from ESI-MS measurements. Although the low yields of amino acid dimers preclude synthetic exploitation, this detection has value in a geochemical context, and adds further interest in the role that aminoxazole chemistry might have played in chemical evolution. In the search for a mechanistic rationale, DFT analyses support the proposal of a catalytic cycle between Gly and Phe with 4 . The computed hypothetical reaction of a racemic mixture of Phe and the $R$-enantiomer of $\mathbf{4}$ shows a diastereoselective bias towards the (S)Phe-(S)-Phe isomer. Overall, the energy barriers to be overcome discard a facile route, albeit the computational analysis should serve as a preliminary toehold illustrating the potentiality of spiranic aminoxazoles as organocatalysts in future explorations.

\section{Acknowledgements}

This work was supported by Junta de Extremadura and Fondo Europeo de Desarrollo Regional (Grants IB16167 and GR18015). We also gratefully acknowledge the Cénits/COMPUTAEX Foundation for providing computing time on the LUSITANIA Supercomputer.

\section{References}

Aakeröy CB, Bahra GS, Brown CR, Hitchcock PB, Patell Y, Seddon K (2008) L-proline 2,5dihydroxybenzoic acid (1/1): a zwitterion co-crystal. Acta Chem Scand 49:762-767. https://doi.org/10.3891/acta.chem.scand.49-0762

Anastasi C, Crowe MA, Powner MW, Sutherland JD (2006) Direct assembly of nucleoside precursors from two- and three-carbon units. Angew Chem Int Ed 45:6176-6179. https:doi.org/10.1002/anie.200601267

Berger M, Schmidtchen FP (1999) Zwitterionic guanidinium compounds serve as electroneutral anion hosts. J Am Chem Soc 121:9986-9993. https://doi.org/10.1021/ja992028k 
Blondeau P, Segura M, Pérez-Fernández R, De Mendoza J (2007) Molecular recognition of oxoanions based on guanidinium receptors. Chem Soc Rev 36:198-210. https://doi.org/10.1039/b603089k

Borsenberger V, Crowe MA, Lehbauer J, Raftery J, Helliwell M, Bhutia K, Cox T, Sutherland JD (2004) Exploratory studies to investigate a linked prebiotic origin of RNA and coded peptides. Chem Biodivers 1:203-246. https://doi.org/10.1002/cbdv.200490105

Budin I, Szostak JW (2010) Expanding Roles for Diverse Physical Phenomena During the Origin of Life. Annu Rev Biophys 39:245-263. https://doi.org/10.1146/annurev.biophys.050708.133753

Cremer D, Pople JA (1975) A General Definition of Ring Puckering Coordinates. J Am Chem Soc 97:1354-1358. https://doi.org/10.1021/ja00839a011

Danger G, Plasson R, Pascal R (2012) Pathways for the formation and evolution of peptides in prebiotic environments. Chem. Soc Rev 41:5416-5429. https://doi.org/10.1039/C2CS35064E

Das B, Srivastava HK (2017) Influence of the local chemical environment in the formation of multicomponent crystals of L-tryptophan with N-heterocyclic carboxylic acids: unusual formation of double zwitterions. Cryst Growth Des 17:3796-3805. https://doi.org/10.1021/acs.cgd.7b00386

Ditchfield R, Hehre WJ, Pople JA (1971) Self-consistent molecular-orbital methods. IX. An extended Gaussian-type basis for molecular-orbital studies of organic molecules. J Chem Phys 54:724-728. https://doi.org/10.1063/1.1674902

Eschenmoser A (2011) Etiology of potentially primordial biomolecular structures: From vitamin B 12 to the nucleic acids and an inquiry into the chemistry of life's origin: A retrospective. Angew Chem Int Ed 50:12412-12472. https://doi.org/10.1002/anie.201103672

Etter MC, MacDonald JC, Bernstein J (1990) Graph-set analysis of hydrogen-bond patterns in organic crystals. Acta Crystal B46:256-262. https://doi.org/10.1107/S0108768189012929

Francl MM, Pietro WJ, Hehre WJ, Binkley JS, DeFrees DJ, Pople JA, Gordon MS (1982) Self-consistent molecular orbital methods. XXIII. A polarization-type basis set for second-row elements. J Chem Phys 77:3654-3665. https://doi.org/10.1063/1.444267

Frisch MJ, Trucks GW, Schlegel HB et al. (2009) Gaussian 09. Revision D.01. Gaussian, Inc, Wallingford, CT, USA

Gordon MS (1980) The isomers of silacyclopropane. Chem Phys Lett 76:163-168. https://doi.org/10.1016/0009-2614(80)80628-2 
Grouiller A, Mackenzie G, Najib B, Shaw G, Ewing D (1988) A novel stereospecific synthesis of 5-amino-1- $\beta$-D-fructofuranosylimidazole-4-carboxamide. J Chem Soc Chem Commun 671-672. https://doi.org/10.1039/C39880000671

Halim MA, Shaw DM, Poirier RA (2010) Medium effect on the equilibrium geometries, vibrational frequencies and solvation energies of sulfanilamide. J Mol Struct (THEOCHEM) 960:63-72. https://doi.org/10.1016/j.theochem.2010.08.027

Hall SR, McMahon B (2006) International tables for crystallography vol G: Definition and exchange of crystallographic data. International union of crystallography. Wiley, New York.

Hariharan PC, Pople JA (1973) The influence of polarization functions on molecular orbital hydrogenation energies. Theor Chim Acta 28:213-222. https://doi.org/10.1007/BF00533485

Hawker JR Jr, Oró J (1981) Cyanamide mediated syntheses of peptides containing histidine and hydrophobic amino acids. J Mol Evol 17:285-294. https://doi.org/10.1007/BF01795750

Hein JE, Tse E, Blackmond DG (2011) A route to enantiopure RNA precursors from nearly racemic starting materials. Nat Chem 3:704-706. https://doi.org/10.1038/nchem.1108

Julian RR, Myung S, Clemmer DE (2005) Do homochiral aggregates have an entropic advantage? J Phys Chem B 109:440-444. https://doi.org/10.1021/jp046478x

Kovács J, Pintér I, Köll P (1995) Direct transformation of D-idose and D-altrose with potassium cyanate into cyclic carbamates of derived glycosylamines. Carbohydr Res 272:255-262. https://doi.org/10.1016/0008-6215(95)00009-I

Krishnamurthy R, Arrhenius G, Eschenmoser A (1999) Formation of glycolaldehyde phosphate from glycolaldehyde in aqueous solution. Orig Life Evol Biosph 29:333354. https://doi.org/10.1023/A:1006698208873

Kubik S (2017) Anion recognition in aqueous media by cyclopeptides and other synthetic receptors. Acc Chem Res 50:2870-2878. https://doi.org/10.1021/acs.accounts.7b00458

Marenich AV, Cramer CJ, Truhlar DG (2009a) Universal solvation model based on solute electron density and on a continuum model of the solvent defined by the bulk dielectric constant and atomic surface tensions. J Phys Chem B 113:4538-4543. https://doi.org/10.1021/jp810292n

Marenich AV, Cramer CJ, Truhlar DG (2009b) Performance of SM6, SM8, and SMD on the SAMPL1 test set for the prediction of small-molecule solvation free energies. J Phys Chem B 113:6378-6396. https://doi.org/10.1021/jp809094y

Müller D, Pitsch S, Kittaka A, Wagner E, Wintner CE, Eschenmoser A, Ohlofjgewidmet G (1990) Chemie von $\alpha$-aminonitrilen. Aldomerisierung von glycolaldehyd-phosphat zu racemischen hexose-2,4,6-triphosphaten und (in gegenwart von formaldehyd) 
racemischen pentose-2,4-diphosphaten: rac-allose-2,4,6-triphosphat und rac-ribose2,4-diphosphat sind die reaktionshauptprodukte. Helv Chim Acta 73:1410-1468. https://doi.org/10.1002/hlca.19900730526

Parker ET, Zhou M, Burton AS, Glavin DP, Dworkin JP, Krishnamurthy R, Fernandez FM, Bada J (2014) A plausible simultaneous synthesis of amino acids and simple peptides on the primordial earth. Angew Chem Int Ed 53:8132-8136. https://doi.org/10.1002/anie.201403683

Pascal R, Boiteau L, Commeyras A (2005) From the prebiotic synthesis of $\alpha$-amino acids towards a primitive translation apparatus for the synthesis of peptides. In: Prebiotic chemistry, Top Curr Chem 259:69-122

Patel BH, Percivalle C, Ritson DJ, Duffy CD, Sutherland JD (2015) Common origins of RNA, protein and lipid precursors in a cyanosulfidic protometabolism. Nat Chem 7:301-307. https://doi.org/10.1038/nchem.2202

Plasson R, Bersini H, Commeyras A (2004) Recycling Frank: Spontaneous emergence of homochirality in noncatalytic systems. Proc Natl Acad Sci USA 101:16733-16738. https://doi.org/10.1073/pnas.0405293101

Powner MW, Gerland B, Sutherland JD (2009) Synthesis of activated pyrimidine ribonucleotides in prebiotically plausible conditions. Nature 459:239-242. https://doi.org/10.1038/nature08013

Powner MW, Sutherland JD, Szostak JW (2010) Chemoselective multicomponent one-pot assembly of purine precursors in water. J Am Chem Soc 132:16677-16688. https://doi.org/10.1021/ja108197s

Powner MW, Zheng SL, Szostak JW (2012) Multicomponent assembly of proposed DNA precursors in water. J Am Chem Soc 134:13889-13895. https://doi.org/10.1021/ja306176n

Pressman A, Blanco C, Chen IA (2015) The RNA world as a model system to study the origin of life. Curr. Biol 25:R953-R963

Reiner H, Plankensteiner K, Fitz D, Rode BM (2006) The possible influence of L-histidine on the origin of the first peptides on the primordial earth. Chem Biodivers 3:611-621. https://doi.org/10.1002/cbdv.200690064

Ribeiro RF, Marenich AV, Cramer CJ, Truhlar DG (2010) Prediction of SAMPL2 aqueous solvation free energies and tautomeric ratios using the SM8, SM8AD, and SMD solvation models. J Comput Aided Mol Des 24:317-333. https://doi.org/10.1007/s10822-010-9333-9

Ritson D, Sutherland JD (2012) Prebiotic synthesis of simple sugars by photoredox systems chemistry. Nat Chem 4:895-899. https://doi.org/10.1038/nchem.1467

Rode BM (1999) Peptides and the origin of life. Peptides 20:773-786. 
Rode BM, Schwendinger MG (1990) Copper-catalyzed amino acid condensation in water-A simple possible way of prebiotic peptide formation. Orig Life Evol Biosph 20:401-410. https://doi.org/10.1007/BF01808134

Ruiz-Mirazo K, Briones C, De La Escosura A (2014) Prebiotic systems chemistry: New perspectives for the origins of life. Chem Rev 114:285-366. https://doi.org/10.1021/cr2004844

Saielli G (2010) Differential solvation free energies of oxonium and ammonium ions: Insights from quantum chemical calculations. J Phys Chem A 114:7261-7265. https://doi.org/10.1021/jp103783j

Saul R, Kern T, Kopf J, Pintér I, Köll P (2000) Reaction of 1,3-disubstituted acetone derivatives with pseudohalides: A simple approach to spiro[4.4]nonane-type bisoxazolidines and -imidazolidines (bicyclic carbamates, thiocarbamates, ureas, and thioureas). Eur J Org Chem 205-209

Schwartz AW (2007) Intractable mixtures and the origin of life. Chem Biodivers 4:656-664

Schwartz AW (2013) Evaluating the plausibility of prebiotic multistage syntheses. Astrobiology 13:784-789. https://doi.org/10.1089/ast.2013.1057

Springsteen G, Joyce GF (2004) Selective derivatization and sequestration of ribose from a prebiotic mix. J Am Chem Soc 126:9578-9583. https://doi.org/10.1021/ja0483692

Steinman G, Lemmon RM, Calvin M (1964) Cyanamide: A possible key compound in chemical evolution. Proc Natl Acad Sci USA 52:27-30. https://doi.org/10.1073/pnas.52.1.27

Surov AO, Voronin AP, Vener MV, Churakov AV, Perlovich GL (2018) Specific features of supramolecular organisation and hydrogen bonding in proline cocrystals: A case study of fenamates and diclofenac. CrystEngComm 20:6970-6981. https://doi.org/10.1039/c8ce01458b

Tilborg A, Norberg B, Wouters J (2014) Pharmaceutical salts and cocrystals involving amino acids: A brief structural overview of the state-of-art. Eur J Med Chem 74:411-426. https://doi.org/10.1016/j.ejmech.2013.11.045

Weissbuch I, Illos RA, Bolbach G, Lahav M (2009) Racemic $\beta$-sheets as templates of relevance to the origin of homochirality of peptides: Lessons from crystal chemistry. Acc Chem Res 42:1128-1140. https://doi.org/10.1021/ar900033k

Weissbuch I, Leiserowitz L, Lahav M (2011) Achiral organic, inorganic, and metal crystals as auxiliaries for asymmetric transformations. Isr $\mathrm{J}$ Chem 51:1017-1033. https://doi.org/10.1002/ijch.201100066

Yaylayan VA, Harty-Majors S, Ismail AA (1999) Investigation of DL-glyceraldehydedihydroxyacetone interconversion by FTIR spectroscopy. Carbohydr Res 318:20-25 
Zhao Y, Truhlar DG (2008) The M06 suite of density functionals for main group thermochemistry, thermochemical kinetics, noncovalent interactions, excited states, and transition elements: Two new functionals and systematic testing of four M06-class functionals and 12 other function. Theor Chem Acc 120:215-241. https://doi.org/10.1007/s00214-007-0310-x 